Review Article

\title{
Malaria Vaccine Adjuvants: Latest Update and Challenges in Preclinical and Clinical Research
}

\author{
Elena Mata, ${ }^{1}$ Aiala Salvador, ${ }^{1,2}$ Manoli Igartua, ${ }^{1,2}$ \\ Rosa María Hernández, ${ }^{1,2}$ and José Luis Pedraz ${ }^{1,2}$ \\ ${ }^{1}$ NanoBioCel Group, Laboratory of Pharmaceutics, School of Pharmacy, University of the Basque Country (UPV/EHU), \\ Vitoria-Gasteiz, Spain \\ ${ }^{2}$ Networking Biomedical Research Center on Bioengineering, Biomaterials and Nanomedicine (CIBER-BBN), Vitoria-Gasteiz, Spain
}

Correspondence should be addressed to José Luis Pedraz; joseluis.pedraz@ehu.es

Received 14 January 2013; Accepted 21 March 2013

Academic Editor: Udai P. Singh

Copyright (C) 2013 Elena Mata et al. This is an open access article distributed under the Creative Commons Attribution License, which permits unrestricted use, distribution, and reproduction in any medium, provided the original work is properly cited.

\begin{abstract}
There is no malaria vaccine currently available, and the most advanced candidate has recently reported a modest $30 \%$ efficacy against clinical malaria. Although many efforts have been dedicated to achieve this goal, the research was mainly directed to identify antigenic targets. Nevertheless, the latest progresses on understanding how immune system works and the data recovered from vaccination studies have conferred to the vaccine formulation its deserved relevance. Additionally to the antigen nature, the manner in which it is presented (delivery adjuvants) as well as the immunostimulatory effect of the formulation components (immunostimulants) modulates the immune response elicited. Protective immunity against malaria requires the induction of humoral, antibody-dependent cellular inhibition (ADCI) and effector and memory cell responses. This review summarizes the status of adjuvants that have been or are being employed in the malaria vaccine development, focusing on the pharmaceutical and immunological aspects, as well as on their immunization outcomings at clinical and preclinical stages.
\end{abstract}

\section{Introduction}

It was almost 50 years ago when the inoculation of attenuated sporozoites evidenced protective immunity and, therefore, the feasibility of developing a cost-effective malaria vaccine. However, the most advanced candidate up to date has only achieved moderate efficacy (30\%).

One of the reasons for the slow progress in developing an effective malaria vaccine is the strong capacity of Plasmodium parasite to evade host's immune response. This ability derives from the genetic complexity of the pathogen, which exhibits genetic diversity as well as antigenic variation during the multistage life cycle. In consequence, immune responses combining both humoral and cellular responses, that target different asexual stages of the Plasmodium live cycle, would be more suitable to achieve host protection against malaria. In addition, vaccines can also be directed to sexual stage for blocking the transmission of the parasite.
Humoral response induces opsonization of sporozoites, blockage of red cell invasion, and elimination of infected cells directly or through antibody-dependent cellular inhibition (ADCI). On the other hand, cellular response is decisive to produce cytokines and immune mediators ( $\mathrm{T}$ helper cells (Th)), as well as to kill infected hepatocytes (cytotoxic CD8 ${ }^{+}$ T lymphocytes, (CTLs)) [1].

Another handicap for malaria vaccine development derives from the traditional strategies of research focused on the antigen-targeting approach, not considering the role of other components of the formulation that can induce and modulate the immune response. Probably several antigen candidates had been abandoned based on the unsatisfactory clinical results obtained because they were inadequately adjuvanted. For example, the most advanced malaria vaccine (RTS,S) did not produce protection when it was formulated with Alum, but it induced moderate protective efficacy of $30 \%$ when formulated with adjuvants such AS02 and AS01 $[2,3]$. 
During the last decades, adjuvants have become increasingly important components for the development of vaccines. They are compounds that enhance and direct specific immune responses, classified based on their principal mechanism of action (Table 1). Immunostimulatory adjuvants can increase specific responses by direct stimulation of the immune system, whereas adjuvants that act as delivery systems carry the antigens to the immune cells. The main advantage of the delivery systems is that they allow the coadministration of immunostimulants and more than one antigen into the same system.

This review summarizes the adjuvants evaluated up to date for the development of an efficient malaria vaccine and focuses on their pharmaceutical and immunological properties, as well as their major advances and remarkable results. The paper includes the adjuvants that are already licensed, those approved for clinical use, and those under preclinical research.

To facilitate the followup and comprehension of the paper, a description of malaria antigen candidates is summarized in Table 2 , as well as a compilation of malaria vaccine candidates clinically tested and classified as a function of the adjuvant (Table 3 ).

\section{Adjuvants for Malaria Vaccines under Clinical Evaluation}

This section describes the adjuvants that have been employed during the clinical development of diverse malaria vaccine candidates, considering the most relevant vaccines and clinical trials.

2.1. Alum. Alum, the noncrystalline gel-like forms of aluminum salts, was the first adjuvant approved for human use around 80 years ago [4]. It is a component of numerous licensed vaccines, such diphtheria-tetanus-pertussis (DTP), hepatitis A and B virus (HAV, HBV), human papilloma virus (HPV), Haemophilus influenza, and Streptococcus pneumoniae [5].

Alum has the capacity to stimulate strong humoral responses (Th2) $[6,7]$. The interaction of Alum with the immune system has not been completely clarified and several mechanisms of action have been proposed. First, it was believed that Alum only produced a depot effect and thereby a sustained release of antigen $[8,9]$. However, several studies have reported a rapid desorption of this adjuvant from the injection site $[10,11]$. What is clear is that the administration of the antigen in a particulate form favors its capture by antigen-presenting cells (APCs) $[12,13]$. Alum has also demonstrated its own immunostimulatory capacity [14-16]; a direct or indirect (mediated by dangerous signals such uric acid) ability of Alum to activate NALP3, a component of the inflammasome complex, has been described [7]. This activation leads to caspase-1 activation, proinflammatory cytokine secretion (IL-1 $\beta$, IL-18, IL-33), and monocyte migration to lymph nodes (LNs) for their differentiation into inflammatory dendritic cells (DCs) $[17,18]$. However, other studies have reached contradictory results and proposed that the inflammasome activation does not contribute to the adjuvanicity of Alum $[19,20]$.

Currently, Alum is the most used adjuvant in the clinical evaluation of malaria vaccines. The first malaria vaccine candidate extensively tested in endemic areas was the Alumadjuvanted SPf66 multistage antigen [21]. With the exception of reducing the incidence of new episodes (28\%) [22], results concluded the presence of short-lived antibodies, low cellular responses and no evidence of protection. Therefore, this candidate was abandoned after 10 clinical trials. The preerythrocytic antigen PfCS102 has also been evaluated in combination with Alum, but no success has been achieved [23]. Slightly better results have been obtained with Alumadjuvanted blood-stage vaccines. $\mathrm{MSP}_{1}-\mathrm{Cl}_{42}$ [24], AMA1$\mathrm{FVO}_{25-545}$ [25], AMA1-C1 [26] and GLURP ${ }_{85-213}$ [27] elicited moderate antibody levels but poor cellular responses (IFN$\gamma$ secretion, lymphoproliferation, and in vitro inhibition of parasite growth) and no protection in field clinical trials. Despite these findings, the clinical research with these antigens continued following their reformulation with other adjuvants and/or combination with other antigens.

Nowadays other Alum-adjuvanted blood-stage antigens are under clinical trials. It has been shown that EBA-175 RII [28] antigen stimulates functional antibody responses, with certain capacity to inhibit in vitro parasite growth and parasite binding to the erythrocytes. MSP $3_{181-276}$ and MSP3 ${ }_{154-249}$ also induced considerable antibody-based humoral responses during Phase I trials. In addition MSP3 ${ }_{154-249}$ also produced cellular responses including IFN- $\gamma$ secretion and lymphoproliferation, leading to Phase II clinical evaluation $[29,30]$. Another Alum-adjuvanted vaccine under Phase II trials is GMZ2 (recombinant protein of MSP3 and GLURP), which elicited considerable antibody levels, including cytophilic ones, cross-reactivity with other malaria antigens, and cell memory during 1 year [31]. The most recent Alum-adjuvanted antigen under clinical evaluation is SE36, which shows promising antibody responses, including 100\% seroconversion after the second dose in adult recipients [32].

With regard to sexual stage vaccines, the transmissionblocking Pf25 and Pv25 proteins (expressed on the surface of ookinetes in the mosquito stage of $P$. falciparum and $P$. vivax, resp.) have been clinically evaluated in combination with Alum. They produced poor immunogenicity and Pf25 induced local reactogenicity $[33,34]$. A Phase I clinical trial is being conducted with Pf 25 conjugated with the recombinant P. aeruginosa ExoProtein A (EPA) and adjuvanted with Alum [35], which demonstrated higher specific antibodies and transmission-blocking activity than Pf25/Alum alone [36] in preclinical studies.

The advantages of Alum are the strong stimulation of the antibody secretion, the extensive experience on clinical safety, the antigen stability, the relative low cost, and the ease to formulate and to scale up. However, it presents significant limitations such as insufficient immunopotentiation in comparison to other adjuvants, incapability to induce appropriate Th1-mediated and CTL cellular responses, and the risk of inducing allergic-type eosinophilic responses and granulomatosis. 
TABLE 1: Classification of adjuvants by their principal mechanism of action.

\begin{tabular}{ll}
\hline Immunostimulants & Delivery systems \\
\hline & Alum \\
Saponins & Emulsions \\
Polysaccharides & Liposomes \\
TLR ligands & ISCOMs \\
Cytokines & Polymeric particles \\
& Virosomes \\
& VLPs \\
\hline
\end{tabular}

2.2. Emulsions. Emulsion-based adjuvants include two types of emulsions, water in oil (w/o) and oil in water $(\mathrm{o} / \mathrm{w})$. In their majority, they employ squalene, in the oily phase, a natural component of cell membranes and precursor of cholesterol.

2.2.1. MF59. MF59 adjuvant, currently licensed for the influenza vaccine, is a fluid o/w nanoemulsion composed of squalene droplets stabilized with Tween 80 and Span 85. MF59 overcomes Alum adjuvant in eliciting potent and balanced antibody responses. Moreover, it stimulates strong $\mathrm{T}$ helper cell responses [37]. Nevertheless, MF59 shows limited ability to induce $\mathrm{CD} 4^{+} \mathrm{Th} 1$ immune responses [38] and polarizes Th2-biased responses [39]. MF59 acts by direct immunostimulation of monocytes, macrophages, and granulocytes to produce cytokines and chemokines [40].

Preclinical research on MF59-adjuvanted malaria vaccines did not provide satisfactory results. A study of mice immunization against PvDBP formulated with MF59 demonstrated that it can elicit antibodies as well as IFN- $\gamma$ secretion; however, antigen formulated with Montanide or AS02A achieved enhanced antibody responses with superior titers and higher capacity to block erythrocyte invasion [41]. Moreover, $\mathrm{MSP}_{-12}$ protein revealed almost no immune response when formulated with MF59 in a mice immunization study [42], low antibodyital and no protection in an Aotus challenge trial [43], as also happened against SERA-1 protein [44]. All these results determined no further progression towards clinical stage with any MF59-based malaria vaccine.

2.2.2. AS03. AS03 adjuvant, registered for human influenza pandemic vaccine, is an o/w emulsion that contains squalene, vitamin $\mathrm{E}$, and Tween 80 . It produces strong antibody levels, $\mathrm{B}$ cell memory, and $\mathrm{CD} 4^{+} \mathrm{T}$ cell [45] responses but, as other squalene based adjuvants, they are mainly Th2 biased. In addition, vitamin $\mathrm{E}$ confers further stimulant properties on AS03 [46] and stimulates sustained antibody responses [47]. The most remarkable use of the AS03 regarding malaria has been its combination with the RTS,S vaccine. Although it elicited a strong antibody response in healthy volunteers, only a moderate protective efficacy of $25 \%$ was reached following challenge [48].

2.2.3. Montanide. Montanide ISA 51 (ISA-51) and Montanide ISA 720 (ISA-720) are w/o microemulsions composed of squalene stabilized with surfactants [49]. Montanides produce strong antibody secretion, $\mathrm{T}$ cell proliferation [50], and balanced Th1/Th2 cytokine profiles [41]. They recruit, activate, and induce migration of APCs to dLNs. Moreover, they interact with cellular membranes favoring the antigen uptake [49]. Furthermore, unlike o/w emulsions, Montanide exerts a depot effect [51].

Several ISA-720 adjuvanted malaria vaccine candidates have been or are currently being clinically evaluated. PfCS102 demonstrated very encouraging results at early doseescalation trials, including the induction of specific and functional antibodies, as well as strong but short-termed $\mathrm{CD}^{+}$and $\mathrm{CD}^{+}$immune responses [23], although it did not induce protective immunity after sporozoite challenge [52]. Another Phase I/IIa clinical trial has been conducted with a preerythrocytic antigen, LSA-3, adjuvanted with ISA-720 or Alum. Although no data has been reported yet, LSA-3/ISA720 has previously demonstrated promising protection on a primate model [53].

Regarding blood-stage vaccines, combination B candidate, comprising recombinant proteins from MSP1, MSP2, and RESA, produced strong $\mathrm{T}$ cell responses and weak antibody levels in both healthy and field volunteers [54]. However, no significant efficacy on parasite growth rate was shown at challenge trials [55]. Similarly, PfCP2.9 evoked high antibody responses but failed in inducing functional activity against parasite [56]. On the contrary, ISA-720 adjuvanted AMA1-FVO $_{25-545}$ [25], AMA1-C1 [57], GLURP ${ }_{85-213}$ [27], $\mathrm{MSP}_{181-276}$ [29], and MSP2-C1 [58] antigens elicited strong antibody levels, including cytophilic subclasses in some cases. $\mathrm{T}$ cell responses were also elicited in healthy volunteers, including in vitro peripheral blood mononuclear cell proliferation, IFN- $\gamma$ secretion, and parasite growth inhibition. However, the MSP2-C1/ISA-720 vaccine trial had to be ended prematurely because of the production of local reactogenicity at the injection site. Besides, the development of AMA1-C1 candidate adjuvanted with ISA-720 was stopped owing to stability concerns [57]. Finally, no data are already available from JAIVAC-1 (combination of proteins $\mathrm{MSP}_{19}$ and $\mathrm{EBA}_{175}$ ), the last ISA-720 adjuvanted blood-stage candidate under Phase I clinical trials.

Regarding the clinical use of Montanide on sexual stage vaccines, it is worth mentioning that although Pf25 and Pv25 adjuvanted with ISA-51 elicited moderate to low antibody responses, respectively, the reported severe local reactogenicity and cases of systemic erythema nodosum (higher severe with Pf25) rendered these candidates for further development [59].

The advantage of the Montanides is their capacity to stimulate both humoral and cellular responses. However, they have been associated with critical drawbacks such as pain and unacceptable reactogenicity at the injection site reported in several studies, certain concerns regarding the stability of the antigens, and the need to develop individually extensive and costly specific emulsification procedures for each antigen. In addition, a risk of induction or exacerbation of inflammatory arthritis in genetically susceptible humans has been described for squalene-based emulsions [60]. 
TABLE 2: Description of malaria antigen candidates.

\begin{tabular}{|c|c|c|}
\hline Life cycle-stage & Vaccine & Description \\
\hline \multirow{8}{*}{ Preerythrocytic } & CSP & Circumsporozoite protein exhibited at the sporozoite surface \\
\hline & PfCS102 & 282-383 sequence of the C-terminal region of CSP from P. falciparum NF54 strain \\
\hline & ICC-1132 & Universal $\mathrm{T}$ and repetitive $\mathrm{B} / \mathrm{T}$ epitopes from CSP fused to $\mathrm{HBcAg}$ and autoassembled as VLPs \\
\hline & RTS,S & $\begin{array}{l}\text { CSP C-terminal extreme containing B and T cell epitopes fused to HBsAg and assembled as } \\
\text { VLP }\end{array}$ \\
\hline & PEV302 & $\begin{array}{l}\text { Virosome containing UK-39 peptide corresponding to the immunodominant NANP repeat } \\
\text { region of CSP }\end{array}$ \\
\hline & LSA-3 & Liver stage antigen 3 \\
\hline & FMP011 & Recombinant protein of LSA-1 from 3D7 strain \\
\hline & ME-TRAP & $\begin{array}{l}\text { Multiepitope (ME) consisted of preerythrocytic fusion antigen consisting of } 17 \mathrm{~B} \text { cell, CD4+, } \\
\text { and CD8+ T cell epitopes from six P. falciparum antigens fused to the T9/96 allele of } \\
\text { (thrombospondin-related adhesion protein) preerythrocytic antigen (TRAP) }\end{array}$ \\
\hline \multirow{17}{*}{ Blood stage } & $\mathrm{MSP} 1-\mathrm{Cl}_{42}$ & $\begin{array}{l}\text { Combination of the alleles FVO and 3D7 of the } 42 \mathrm{Kda} \text { fragment of the merozoite surface } \\
\text { protein } 1 \text { (MSP-1) }\end{array}$ \\
\hline & AMA1-FVO $25-545$ & $\begin{array}{l}\text { Recombinant 25-545 sequence of the merozoite apical membrane antigen } 1 \text { (AMA-1) from } \\
\text { FVO strain }\end{array}$ \\
\hline & AMA1-C1 & Combination of equal mixtures of the recombinant AMA-1 from FVO and 3D7 strains \\
\hline & $\mathrm{EBA}_{175}$ RII & Region II domain of the erythrocyte-binding antigen 175 parasite protein \\
\hline & $\mathrm{MSP}_{181-276}$ & C-terminal conserved region from MSP- 3 from FC27 strain \\
\hline & $\mathrm{MSP}_{154-249}$ & C-terminal conserved region from MSP-3 from 3D7 strain \\
\hline & SE36 & Recombinant molecule of serine repeat antigen 5 (SERA5) \\
\hline & PvDBP & $\begin{array}{l}P . \text { vivax Duffy binding protein, which binds the Duffy blood group antigen as the obligate } \\
\text { receptor for erythrocyte invasion }\end{array}$ \\
\hline & Combination B & $\begin{array}{l}\text { Combination of recombinant proteins from MSP1, MSP2, and RESA (ring-infected erythrocyte } \\
\text { surface antigen) }\end{array}$ \\
\hline & PfCP2.9 & $\begin{array}{l}\text { Recombinant protein consisted of domain III of AMA1 and } \mathrm{MSP}_{19} \text { from } 3 \mathrm{D} 7 \text { and FVO strains, } \\
\text { respectively }\end{array}$ \\
\hline & MSP2-C1 & Combination of recombinant allelic MSP-2 from 3D7 and FC27 \\
\hline & JAIVAC-1 & Combination of proteins $\mathrm{MSP}_{19}$ and $\mathrm{EBA}_{175}$ \\
\hline & $\mathrm{SC}_{26} 42$ & $\begin{array}{l}\text { Hybrid antigen containing the C-terminal fragment of } P \text {. falciparum precursor to the major } \\
\text { surface antigens (PMMSA) and the tetrapeptide repeats of CSP }\end{array}$ \\
\hline & FMP1 & Recombinant $\mathrm{MSP}_{42}$ from $3 \mathrm{D} 7$ strain \\
\hline & FMP2.1 & Recombinant AMA-1 from 3D7 strain \\
\hline & BSAM-2 & $\begin{array}{l}\text { A mixture in equal amounts of four proteins corresponding to the } 3 \mathrm{D} 7 \text { and FVO alleles of } \\
\text { MSP-1 and AMA-1 }\end{array}$ \\
\hline & PEV301 & Virosome containing $\mathrm{AMA}_{49}$-C1 peptide derived from loop I of domain III of AMA-1 \\
\hline \multirow{2}{*}{ Sexual stage } & Pf25 & Protein expressed on the surface of ookinetes of $P$. falciparum \\
\hline & Pv25 & Protein expressed on the surface of ookinetes of $P$. vivax \\
\hline \multirow{6}{*}{ Multistage } & SPf66 & Three blood-stage sequences and repetitive sequences of preerythrocytic CSP \\
\hline & GLURP $_{85-231}$ & $\begin{array}{l}85-231 \text { sequence of glutamate rich protein (GLURP) expressed both in preerythrocytic and } \\
\text { blood stage }\end{array}$ \\
\hline & GMZ2 & Recombinant protein of MSP3 and GLURP \\
\hline & PEV3A & Combination by coadministration of PEV301 and PEV302 \\
\hline & Polyprotein & $\begin{array}{l}\text { Long polyprotein consisted of } 6 \text { antigens; LSA-3, sporozoite threonine and asparagine-rich } \\
\text { protein (STARP), liver stage exported protein } 1 \text { (Exp-1), preerythrocytic/sexual stage Pfs16, } \\
\text { TRAP, and LSA-1 }\end{array}$ \\
\hline & NMRC-M3V-Ad-PfC & Combination of two human adenoviruses Ad5 encoding CSP and AMA-1, respectively \\
\hline
\end{tabular}




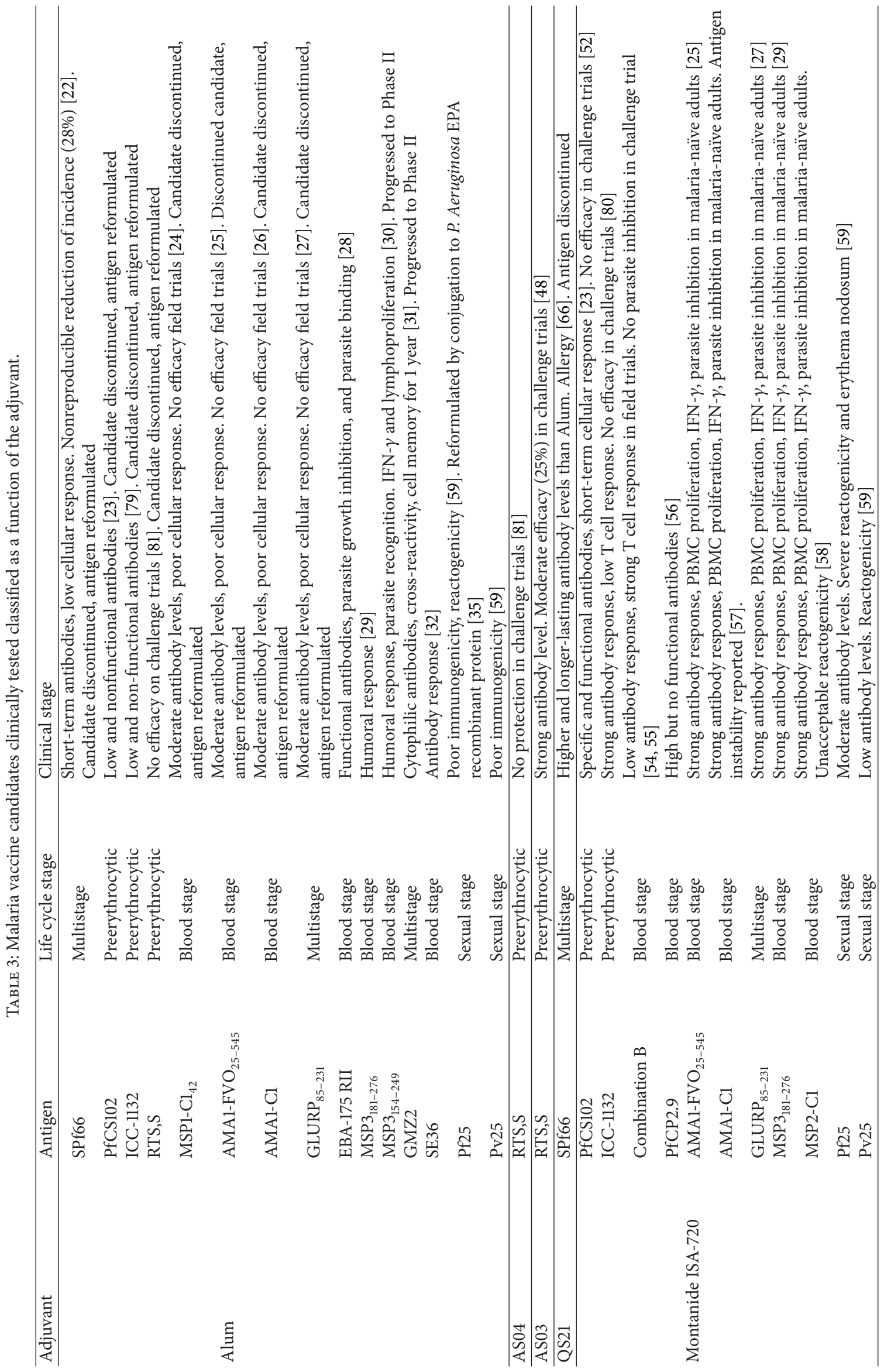




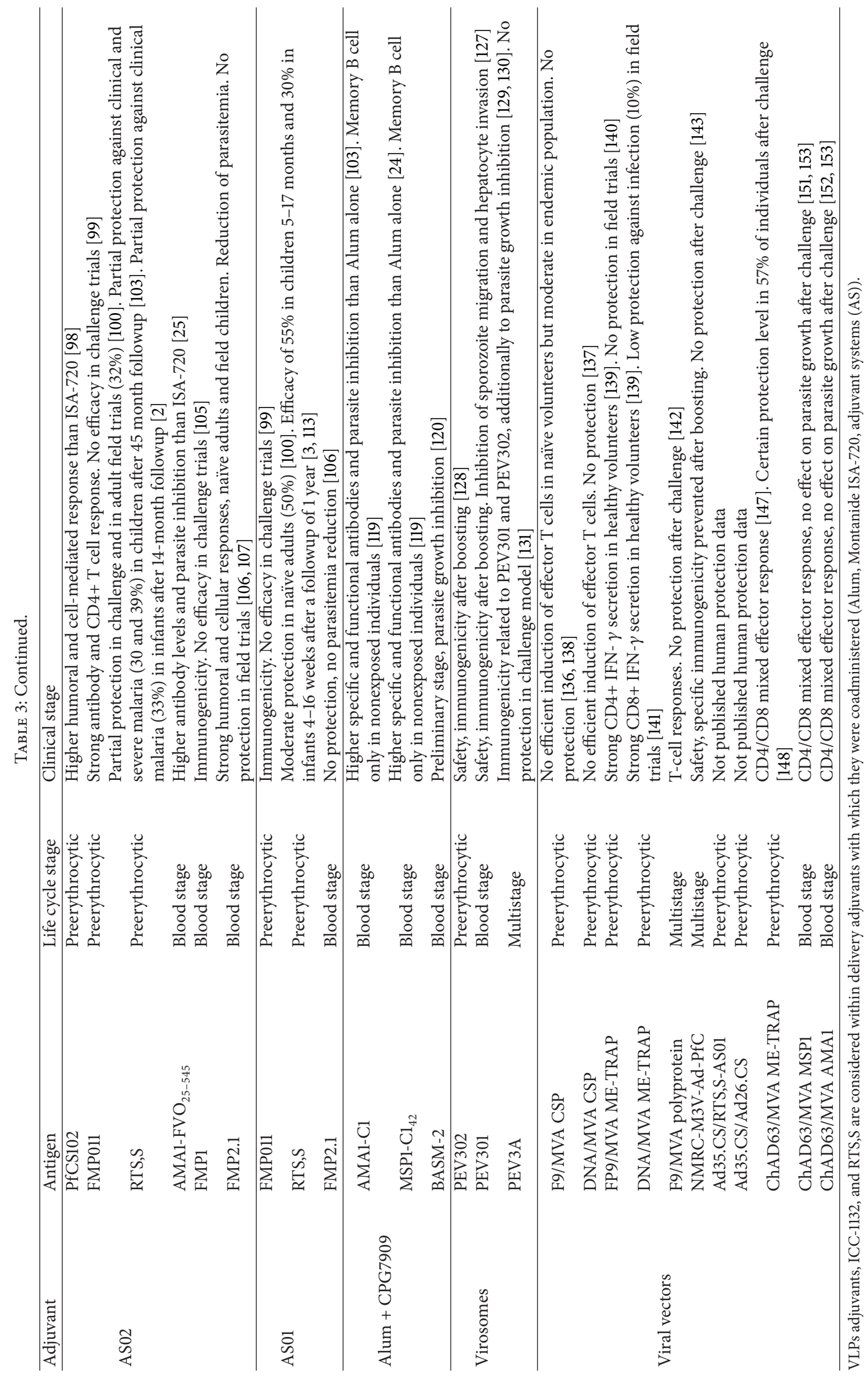


2.3. Saponins. Saponins are natural glycosides of steroids or triterpenes widely distributed in plants and animals. Quil-A, an extract of Quillaja saponaria, and its derivatives constitute the most extensively used saponins for adjuvant purposes [61]. Although saponins have been widely employed as adjuvants and they are registered for several veterinary vaccines [62], their inclusion into human vaccines has been precluded due to their associated toxicity [63]. QS21, one of the highly purified fractions isolated from Quil-A, exhibits the maximal adjuvanticity with lower toxicity. Saponins stimulate specific humoral and cellular immune responses including Th1 cytokines, cytophilic antibodies, and strong antigen-specific CTL responses [64]. They interact with the cell membrane of APCs gaining the endogenous presentation pathway [65].

The potential of QS21 as an adjuvant for malaria vaccine development was evaluated solely once at clinical stage using the SPf66 multistage antigen. This candidate overcame the immunogenicity elicited when formulated with Alum and it induced higher and longer-lasting antibody levels. However, $2.3 \%$ of the individuals developed severe vaccine allergy, an important complication for a prophylactic vaccine [66].

Immunostimulating complexes (ISCOMs), whose principal component is Quil-A, comprise micellar cage-like particles of about $40 \mathrm{~nm}$ spontaneously formed upon mixing antigens with saponins, phospholipids, and cholesterol [67]. ISCOMs are capable of boosting humoral and cellular responses by both parenteral and mucosal routes $[68,69]$. ISCOM adjuvants induce the recruitment and activation of APCs, increase MHC II expression on APCs, enlarge the antigen presentation at dLNs, enhance cross-presentation, trigger the secretion of cytokines such as IL-2, IL-6, and IFN$\gamma$, and generate CD4+ and CD8+CTL responses [67, 70].

ISCOM-based malaria vaccines have reported good results during preclinical investigation. An adjuvant trial against the hybrid protein $\mathrm{SC}_{26} 42$ in rabbits demonstrated that ISCOM formulation elicited high but short-duration antibodies [71]. On the other hand, two fusion proteins including the antigen Pf155/RESA, ZZ-M3 and ZZ-M5, coupled to preformed influenza virus membrane glycoprotein derived ISCOMs induced long-lasting antibody responses comparable to those obtained with Freund's adjuvant [72]. A more recent immunization study against RESA synthetic peptide entrapped into ISCOMs demonstrated the induction of high levels of high-affinity antibodies in mice [73]. Nevertheless, clinical development of ISCOM-based vaccines has been discouraged due to safety concerns, such as the feeling of mild pain at injection site in a Phase I trial [74]. Besides, ISCOMs possess other disadvantages regarding instability, manufacture, and costs.

2.4. Virus-Like Particles. Virus-like particles (VLPs) are formed by the self-assembly of recombinant viral capsid proteins, maintaining a similar structure and morphology. VLPs cannot replicate and are noninfectious, as they do not incorporate genetic material, constituting a safer alternative to attenuated viruses. Antigens can be incorporated in several ways, either included into the genetic material that encodes for the capsid proteins or chemically conjugated to preformed VLP [75]. VLPs can elicit strong humoral and cellular responses, which are supported by their capacity to cross-link B-cell receptors [76], as well as to enter endogenous crosspresentation pathway [77]. Nowadays, there are two VLPbased licensed vaccines, one against HBV, expressing HBsAg antigen, and another one against HPV, expressing the major capsid protein L1 [78].

Two VLP-based malaria vaccine candidates employing preerythrocytic antigens have been clinically evaluated. ICC1132 candidate comprises the truncated self-assembling HBV core protein ( $\mathrm{HBcAg})$. It includes $\mathrm{T} 1$ cell epitopes and $\mathrm{B}$-cell epitopes from immunodominant CS repeat region inserted in the central loop of $\mathrm{HBcAg}$ and CSP universal T epitope fused to the C terminus. ICC-1132 formulated with Alum did not elicit optimal antibody responses in magnitude and parasite recognition [79]. Moreover, ICC-1132 formulated with ISA720 triggered specific antibodies and modest $\mathrm{T}$ cell responses, even though no protection was evidenced [80].

The other candidate, RTS,S, consists of the RTS hybrid polypeptide from CSP containing B and T cell epitopes fused to the HBsAg (S), assembled as VLPs. Initial trials with RTS,S formulated with Alum, AS03, or AS04 adjuvants did not show encouraging results $[48,81]$. Despite this, the strategy to codeliver RTS,S with more clinically advanced adjuvant systems, AS02 and AS01, has led to the most promising malaria vaccine results up to date $[2,3]$.

The main problems related to the extensive use of VLPbased vaccines are the constraint to incorporate large epitopes owing to increased difficulties for VLP assembling, the biotechnological manufacturing processes instead of chemical synthesis of the antigen, and the requirement of specific particle constructs for each virus-derived VLP and disease. In addition, VLPs have demonstrated a loss of efficiency on boosting doses due to the generation of neutralizing antibodies against capsid proteins [82].

2.5. Toll-Like Receptors. The pattern recognition receptors (PRRs) present on APCs recognize the pathogen-associated molecular patterns (PAMPs), which are highly conserved molecular structures shared by some microorganisms [83]. PRRs mediate numerous immune mechanisms, such as opsonization, phagocytosis, apoptosis, activation of the complement cascade, and release of cytokines and chemokines $[84,85]$.

The best-known PRR family comprises toll-like receptors (TLRs) [86], which are predominantly expressed by the first, line professional phagocytes (neutrophils, macrophages, and DCs). Ten TLRs have been identified in humans. TLRs 1, $2,4,5$, and 6 are expressed on cell surface and recognize extracellular microbial structures, whereas TLRs 3, 7, 8, and 9 are expressed intracellularly and recognize viral and bacterial nucleic acids [87]. PAMPs recognition by APCs triggers the transcription of nuclear factor $\mathrm{kB}(\mathrm{NF} \kappa \beta)$, interferon regulatory factors (IRF), and activator protein 1 (AP-1), which in turn induces the expression of inflammatory cytokines, type I interferons, and chemokines [88]. Moreover, TLR engagement promotes DCs differentiation and maturation, antigen 
presentation and upregulation of costimulatory molecules (CD40, CD70, CD80 and CD86) and secretion of cytokines (IL-1, IL-6, IL-12, and TNF) [89, 90]. Depending on the activated TLR, naïve T cells expand and differentiate towards Th1 or Th2 subsets, leading to $\mathrm{CD} 4^{+}$or $\mathrm{CD} 8^{+} \mathrm{T}$ cell activation and the induction of high memory $\mathrm{T}$ cell responses. In addition, TLR binding on $\mathrm{B}$ cells induces their activation, proliferation, and expression of costimulatory molecules [91]. Therefore, TLR ligands play an important role for linking the innate and adaptive responses.

2.5.1. MPL and Combinations. The 3-O-decylated monophosphoryl lipid A (MPL) immunostimulant is a derivative of the lipopolysaccharide (LPS) endotoxin expressed in the outer membrane of Salmonella minnesota. It is a TLR4 agonist and induces a potent stimulation of the Th1 responses, characterized by the secretion of proinflammatory cytokines and cytotoxic antibodies and the activation of CTLs [92]. MPL-including adjuvant formulations (mainly AS04, AS02, and AS01) are currently under clinical evaluation for several vaccines against cancer and other infectious diseases.

AS04 adjuvant system, which consists of the combination of MPL and Alum, is currently licensed for human HPV and $\mathrm{HBV}$ vaccines. In comparison to Alum, AS04 induces earlier and longer-lasting antibodies [93], and it enhances cellmediated responses [94]. RTS,S candidate has also been clinically tested when formulated with AS04 adjuvant, although low protection was achieved in naïve challenge model [81].

AS02, an o/w emulsion containing MPL and QS21, is currently under clinical investigation for several infectious diseases (malaria, HBV, and S. pneumoniae) [95, 96] and cancer [97] vaccines. With regard to malaria, AS02 has been tested with several candidates. The preerythrocytic antigen PfCS102, exhibited higher humoral and cell-mediated responses, including specific $\mathrm{CD}^{+} \mathrm{T}$ cell and IFN- $\gamma$ secretion, when AS02 was used instead of ISA-720 [98]. In spite of those data, the adjuvant formulation chosen for further evaluation was the latter one, and it did not result in much success [52]. FMP011 candidate (recombinant LSA-1 from 3D7 strain) induced strong antibody and IL- $2 / \mathrm{IFN}-\gamma$-secreting $\mathrm{CD} 4^{+} \mathrm{T}$ cells when adjuvanted with AS02, although no protection was achieved after sporozoite challenge [99]. Remarkably, RTS,S/AS02 candidate showed very high protection (85\%) in early trials with naïve volunteers [48]. However, a dramatic decrease in protection was reported in repeated trials (32\%) [100]. Field trials in adults revealed high but very short-term protection (71\% during first 2 months) [101], but further trials demonstrated only partial protection (32\% over 6 months) [102]. On the other hand, trials on children evidenced moderate efficacy against clinical, infection and severe disease (30, 45 and 58\%, resp.) during 6 months and a maintained efficacy over 45 months against clinical and severe disease (30 and $39 \%$, resp.) [103]. The reformulated pediatric RTS,S/AS02D has reported $66 \%$ of efficacy against infection in infants aged 8-18 weeks after 6 months of followup [104], and an efficacy of $33 \%$ against clinical malaria over 14 months of followup [2].

In the case of blood-stage candidates, AMA1-FVO $25-545$ produced greater antibody levels and parasite growth inhibition rate when adjuvanted with AS02 in comparison to
Alum or Montanide [25]. FMP1 (recombinant $\mathrm{MSP}_{42}$ from 3D7) formulated with AS02 evidenced no efficacy on a proof-of-concept trial even though it had previously demonstrated safety and immunogenicity [105]. On the contrary, FMP2.1/AS02 (recombinant AMA-1 from 3D7) has shown potent humoral and cellular responses in naïve volunteers and malaria-exposed children [106], and although no protection was achieved in field trials, it induced significant reduction in parasitemia (suggesting partial biological effect) [107], and it is being further evaluated.

AS01 adjuvant system is a liposomal formulation containing MPL and QS21. It is being used in clinical research for the development of malaria, tuberculosis (TB), and HIV vaccines [108, 109]. AS01 elicits potent humoral and cell-mediated responses, including CTL responses. Moreover preclinical data suggest that AS01 surpasses AS02 on its adjuvant effect $[110,111]$. Concerning malaria vaccine clinical research, the preerythrocytic candidate FMP011 adjuvanted with AS01 failed to induce protection although immunogenicity was proved, as previously happened with AS02 [99]. On the other hand, RTS,S candidate formulated with AS01 has demonstrated enhanced immunogenicity and protection in comparison to RTS,S/AS02 in naïve adult challenge $(50 \%$ versus 32\%) [100] and in field trials with children 5-17 months of age (53\% versus 30\%) [112]. A pivotal Phase III has been completed in children/infants (5-17 months and 612 weeks, resp.). First data corresponding to the older group showed an efficacy of $55 \%$ after a followup of 12 months [113]. However, recent results from the latter group have evidenced only a 30\% efficacy [3]. Nevertheless, these are the most promising data during the last decade and they have rendered RTS,S/AS01 as the most advanced malaria vaccine, which is still planned to be reviewed in 2015 for a policy recommendation. With regard to blood stage, FMP2.1 antigen adjuvanted with AS01 evidenced neither protection nor parasitemia-decreasing ability, unlike AS02 [106].

Overall, with the exception of certain local reactogenicity, MPL-based adjuvants are safe and well tolerated. Therefore, their limitations are reduced to the complexity of their composition and the implications related to the inclusion of natural immunostimulants.

2.5.2. Immunostimulatory Oligonucleotides. Synthetic CpG oligodeoxynucleotides (ODNs) are considered as immunostimulant sequences (ISS). They comprise short synthetic DNA molecules containing unmethylated CpG motifs (cytosine phosphoguanosine dinucleotides common in bacteria and virus) [114]. CpG ODNs possess a high potential to induce innate immunity as well as specific humoral and Th1-cell mediated responses [115]. For this reason, CpG ODNs have also been postulated as adjuvants for cancer [116] and allergy [117] vaccines. CpG ODNs mediate their immunostimulatory capacity through the TLR9 (receptors expressed on human plasmacytoid DCs (pDCs) and B cells), promoting Thl-biased CD $4^{+} \mathrm{T}$ cell and CTL responses.

Regarding malaria, CPG7909 has been clinically tested in combination with carrier adjuvants in order to increase 
and modulate the immune response. AMA1-C1 and MSP1C1 blood-stage candidates formulated in Alum + CPG7909 induced enhanced specific and functional antibodies that possessed higher capacity for in vitro inhibition of parasite growth in comparison to Alum alone $[24,118]$. However, the capacity of CPG7909 to induce specific memory B cells was only shown in naïve individuals [119]. Preliminary in vitro growth inhibition has also been reported in a more recent trial with BSAM-2 candidate (a mixture of equal amounts of four proteins corresponding to the 3D7 and FVO alleles of MSP1 and AMA-1) formulated into same combination of Alum+CPG7909 adjuvants [120].

Even though clinical trials indicate that CpG ODNs are relatively safe and well tolerated, they have been associated with increased adverse events and local reactogenicity [121]. Moreover, autoimmune responses related to CpG ODNs have been described in preclinical studies [122]. Despite this, it is believed that formulating CpG ODNs in the appropriate adjuvant delivery system may improve their risk-benefit balance and facilitate their approval for human use.

2.6. Virosomes. Virosomes are reconstituted membranes formed from enveloped viruses after viral disruption, so they lack the genetic material. The viral envelope from the virosomes is used as a platform to insert other viral or nonviral components by surface adsorption or integration into the lipid membrane [123]. Virosomes have demonstrated to induce both humoral and cellular responses [124]. The currently licensed virosome-based vaccines (HAV and influenza) comprise immunopotentiating reconstituted influenza virosomes (IRIVs). IRIVs are proteoliposomes composed of purified hemagglutinin (HA) and neuraminidase (NA) from influenza virus intercalated within the phospholipid bilayer [125].

The presence of the HA in the IRIV favors the interaction with the immune cells [126], leading to the antigen presentation into MHC class I and II molecules and subsequent activation of both humoral and cellular immune responses $[123,127]$.

Different IRIV formulations have been evaluated in malaria vaccine clinical trials. Virosomal formulation PEV301 containing AMA49-C1 peptide and PEV302 containing UK-39-peptide have evidenced safety and antibodybased immunogenicity after boosting [128]. Besides, UK-39 immunized individuals developed antibodies able to inhibit the sporozoite migration and hepatocyte invasion in vitro. Likewise, coadministration of both formulations, called as PEV3A, did not interfere with the immunogenicity of each formulation [129], and a reduction in the parasite growth rate was reported [130]. Nevertheless, no protection after challenge was observed [131].

2.7. Viral Vectors. Viral vectors can act as delivery systems by carrying the genetic material encoding for antigens, which will be expressed after immune cell entering [132]. They induce efficient cellular immunity, Th, and CTL, as a consequence of the expression of encoded antigens through MHC-I pathway, as well as antibody responses [133, 134].
Viral vectors are frequently used in heterologous prime-boost immunization regime, in which different vaccine technologies are alternated as priming and boosting.

Viral vectors include DNA and RNA viruses, and the most advanced are poxvirus, adenovirus and flavivirus [135]. There is only one viral vector-based vaccine approved for human use (Imojev, a recombinant yellow fever virusvectored vaccine against Japanese encephalitis). Several virus vectored vaccines are under clinical development (malaria, tuberculosis, HIV, and cancer) [134]. Regarding malaria, viral vectors are becoming one of the most prolific strategies undergoing clinical development. They involve attenuated fowlpox virus strain FP9 and modified virus Ankara (MVA) poxviruses, human/simian adenoviruses (Ad), and their combinations.

2.7.1. Poxviruses. In a Phase Ia trial, FP9/MVA CSP and DNA/MVA CSP candidates did not reach an efficient $\mathrm{T}$ cell activation, and no protection was generated after challenge $[136,137]$. However, IFN- $\gamma$-secreting $\mathrm{CD}^{+}$and $\mathrm{CD} 8^{+} \mathrm{T}$ cells were activated in a posterior Phase Ib trial in Gambia [138], probably due to the natural priming ability of the vectors.

FP9/MVA ME-TRAP and DNA/MVA ME-TRAP strategies induced strong cell-mediated IFN- $\gamma$ secretion in healthy volunteers, biased towards CD4 for F9/MVA regime and CD8 for DNA/MVA [139]. Further studies in endemic areas revealed no protection against F9/MVA ME-TRAP [140], and an efficacy of $10 \%$ for reducing the time of infection against DNA/MVA ME-TRAP [141].

FP9/MVA polyprotein (6 antigens) candidate exploits the poxviruses' capacity to encode large inserts. Unfortunately, it failed in challenge exposition although it elicited $\mathrm{T}$ cell responses, and it was discontinued [142].

2.7.2. Adenoviruses. A clinical trial with human Ad subtype 5 (Ad5) encoding CSP and AMA-1 (two different vectors), called NMRC-M3V-Ad-PfC, could not achieve sterile protection after challenge [143] Moreover, boosting resulted in even less malaria-specific immunogenicity, which could be related to the anti-Ad5 response induced by the priming vaccination.

Ad35 is less immunogenic than Ad5 but its seroprevalence in Africa is significantly lower (20\% versus 95\%). There are currently two vaccines employing Ad35 vector, Ad35.CS and Ad35.CS/RTS,S-AS01, undergoing Phase I/II trials. It has been already described that they produce strong $\mathrm{B}$ and $\mathrm{T}$ immune responses in primates, including sustained $\mathrm{T}$ cell response for at least 6 months for the latter one $[144,145]$.

Another human Ad with lower seroprevalence (below 20\%), Ad26, has entered the clinical stage after showing more potency and long-lasting $\mathrm{T}$ cell responses in mice using a heterologous prime-boost regime, Ad35.CS/Ad26.CS [146].

Simian adenovirus ChAd63 has become an alternative to human Ad because there are no significant preexisting neutralizing antibodies in humans. ChAd63 vector in heterologous prime-boost regime using MVA as boosting is currently undergoing several malaria vaccine clinical trials at different stages and targeting preerythrocytic or blood stages (ME-TRAP, MSP1, AMA1, CSP). ChAD63/MVA ME-TRAP 
(currently under Phase IIb) has demonstrated unprecedented $\mathrm{T}$ cell CD4/CD8 effector responses [147] and a degree of protection of $57 \%$ after challenge in healthy volunteers [148]. This vaccine strategy has previously shown protection in mice [149], as well as sustained antibodies, T-cell cytokines and improved CD8 multifunctional responses in macaques [150]. ChAD63/MVA MSP1 has demonstrated some antibody secretion and very high mixed CD4/CD8 T cell induction in a Phase I study [151], as well as ChAD63/MVA AMA [152], but no effect on parasite growth rate was observed following challenge [153].

\section{Adjuvants under Preclinical Development}

The following section describes adjuvants with potential interest for the design of malaria vaccines that have been evaluated in preclinical studies.

3.1. Liposomes. Liposomes are synthetic phospholipid spheres ranging from nano-to micrometer size, comprising uni or multilipid layers, often stabilized with cholesterol [154]. Liposomes are delivery systems that carry antigens or adjuvants encapsulated into the aqueous core (hydrophilic molecules), adsorbed to the surface (lipophilic molecules) or integrated into the lipid layers (amphiphilic molecules) [155]. Although they can provide humoral and cellular immune responses, there is not any liposomal vaccine commercially available.

Liposomal adjuvanticity is dependent on the number of lipid layers, charge, size, composition, and preparation method. Therefore, its immunogenicity can be modulated by the addition of ligands, antigens, or another type of lipids [123]. The most immunogenic liposomes are the cationic adjuvant formulations (CAF), particularly those made of dimethyl dioctadecyl ammonium (DDA) combined with the modulating and stabilizer glycolipid trehalose dibehenate (TDB). This formulation, known as CAF01, produced cellmediated responses and promising antibody responses in a mouse model [156]. Immunization studies with $P$. yoelii $\mathrm{MSP}_{19}$ antigen have demonstrated higher antibody levels (IgG1 and IgG2a) in vitro cell-mediated IFN- $\gamma$ secretion and earlier parasitemia clearance than Alum. In addition, significant protection was achieved after challenge (lower parasitemia in comparison to unvaccinated group) [157]. In fact, PfAMA-1 and GMZ2 malaria candidates formulated with DDA/TDB almost entered clinical stage, but they were discontinued after toxicological studies [158].

The main drawbacks of liposomes are related to their stability, manufacturing process, and high costs. Besides, they require the inclusion of immunostimulatory molecules. Additionally, pain at injection site can also be a limitation in some liposomal vaccines.

3.2. Polymeric Particles. Polymeric particulate delivery systems are spherical structures ranging from nano-to micrometer size and usually made of biodegradable polymers. In addition to the controlled release [159], biodegradable particles can improve the response of poor immunogenic antigens after parenteral and mucosal vaccination [160, 161], and allow the codelivery of immune-stimulating adjuvants [162].
Although there are several microsphere-based marketed products [163], they have been barely studied in clinics and results have not been very encouraging.

Various polymers have been evaluated as particulate vaccine delivery systems, such as poly- $\varepsilon$-caprolactone, poly- $\gamma$ glutamic acid, starch, alginate, and chitosan. However, polylactic-co-glycolic acid (PLGA) [164] is the most advantageous polymer due to its biodegradability and biocompatibility [165], and it has been approved for human use (FDA) for various applications. PLGA particles can elicit strong antibody responses with neutralizing capacity, $\mathrm{T}$ cell-mediated responses like lymphoproliferation and cytokine secretion, and CTL responses $[166,167]$.

Several mechanisms of action can support the adjuvant effect of these particles. They can act as a depot at the site of injection, delivering the antigen during long periods of time. On the other hand, they can be taken up by immune cells, a process that can be influenced by the shape, size, hydrophobicity, or charge of the particles. Finally, it has also been proposed that polymeric particles can activate the NALP3 inflammasome for the activation of caspase- 1 and secretion of IL1 $\beta$.

With regard to malaria, several preclinical studies have been carried out using polymeric particles entrapping synthetic peptides using different immunization routes. Subcutaneous (sc) route produced humoral and cellular responses comparable to those of IFA adjuvant [168]. Oral administration was comparable to Alum, although the reported cytophilic antibody secretion indicated the capability to induce cellular responses [169]. Nasal immunization evidenced similar antibody secretion compared to CFA/IFA, and it also elicited cytophilic antibody and IFN- $\gamma$ secretion [170]. Intradermal immunization produced a 10 -fold increase of the response when compared to the sc route [171], and it also overcame Montanide's subcutaneous administration [167].

The major drawback for the progression of polymeric particles towards clinics is the difficulty to scale up and to develop cost-effective individual manufacturing processes under aseptic good manufacturing practices (GMPs).

3.3. Polysaccharides. Microbial carbohydrates (glucans, dextrans, glucomannans, galactomannans, levans, and xylans) are signaling molecules for immune system, which can act as potent immunostimulants [172].

Regarding malaria, different MSP antigens from the blood stage have been tested in murine models, formulated with MPI (microparticulate $\gamma$ - and $\delta$-inulin) and algammulin (hybrid particle resulted from the cocrystallization of Alum and inulin) adjuvants. MPI induced an immune response comparable to CFA in terms of antibody levels (total and subclasses), in vitro splenocyte activation (secretion of IFN$\gamma$ and IL-12), and protection against challenge in mice [173]. In addition to the safety and immunological properties, MPI possesses other considerable advantages, such as heat stability, long shelf life, and extremely endotoxin-free purity.

3.4. TLR Immunostimulant Ligands. As it has been mentioned before, TLR agonists exhibit high potential for prophylactic and therapeutic vaccine purposes for inflammatory 
diseases and cancer [174]. In addition to MPL and CpG, other TLR ligands and synthetic analogues are currently under development.

3.4.1. Imidazoquinolines. Imidazoquinoline compounds comprise the small synthetic molecules imiquimod (R-837) and resiquimod (R-848), which are TLR7 and TLR7/8 ligands, respectively [175]. It has been shown that imidazoquinolines can improve both antibody and $\mathrm{T}$ cell responses following diverse administration routes [176, 177]. In addition, topical imiquimod has demonstrated efficacy in human leishmaniasis [178], and it is already licensed for the treatment of malignant and nonmalignant skin disorders. With regard to malaria, the topical administration of imiquimod with the PfCS peptide elicited strong parasitespecific antibody production, $\mathrm{CD}^{+} \mathrm{T}$ cell responses, and protection in a rodent challenge model [179].

3.4.2. Flagellin. Flagellin, the main component of flagellar structure in motile bacteria, is recognized by TLR5 and acts as a potent immune activator [180].

Flagellin has been evaluated in combination with several malaria recombinant vaccine candidates. Immunization with P. vivax MSP-1 ( $\left.\mathrm{PvMSP}_{19}\right)$ fused to flagellin elicited strong, functional, and long-lasting antibody-mediated responses, similarly to $\mathrm{PvMSP}_{19}$ emulsified with CFA [181]. However, the immune response was biased towards Th2. This fact could be modulated by the inclusion of additional adjuvants such as TLR9 agonists. Besides, immunization with $P$. falciparum $\mathrm{PfMSP}_{19}$ fused to flagellin induced high antibody levels that efficiently inhibited the in vitro parasite growth [182]. Moreover, the $\mathrm{CS}_{280-288}$ protein $\left(\mathrm{CD}^{+} \mathrm{T}\right.$ cell epitope from the CSP) from $P$. yoelii induced CS-specific $\mathrm{CD}^{+} \mathrm{T}$ cell responses when combined with flagellin and in the absence of any conventional adjuvant [183].

3.4.3. TLR3 Agonists. TLR3 is activated by the doublestranded RNA (dsRNA) produced during the replication of most viruses, and their agonists can be considered as potential adjuvants for vaccines targeting strong cellular immune responses. Polyinosinic:polycytidylic acid (polyI:C) is a synthetic analogue of viral dsRNA molecules that activates TLR3 and other non-TLR PRRs [184].

With regard to malaria, PfCSP plus polyI:C produced specific robust and functional antibodies, as well as improved $\mathrm{CD} 4^{+} \mathrm{T}$ cell responses in comparison to $\mathrm{RTS}, \mathrm{S} / \mathrm{AS} 01 \mathrm{~B}$ vaccine in primates [185]. These data support the fact that an appropriate formulation can enhance $\mathrm{CD} 8^{+} \mathrm{T}$ cell priming (which plays a major role on liver stage), providing an alternative for the development of a preerythrocytic vaccine. The major drawback of polyI:C could be its toxicity, as it has been reported in clinical studies of leukemia [186]. For this reason, developing polyI:C derivatives with improved activity and safety, such as PolyICLC or PolyI: $\mathrm{C}_{12} \mathrm{U}$, has become a priority in this field.

3.4.4. Synthetic TLR4 Ligands. TLR4 receptors are present in DCs, macrophages, and other nonimmune cells. The TLR4 agonist glucopyranosyl lipid A (GLA) is a new synthetic lipid A. GLA can be formulated in solution or as an o/w stable emulsion (GLA-SE). It has been recently reported that GLASE produces high immune responses in terms of total IgG and IgG2 antibodies levels, parasite-recognizing antibodies, IFN- $\gamma$ secretion and number of long-lived plasma cells in comparison to other TLR agonists in a murine immunization study with GMZ2 malaria candidate [187].

On the other hand, OM-174, a chemically synthesized soluble triacylated partial structure of lipid A, has demonstrated to elicit strong antibody and CTL responses in mice when combined with the $P$. berghei CSP long-synthetic-peptide (LSP) based malaria vaccine [188].

3.4.5. IC31. IC31 is a novel TLR9 agonist that combines the immunostimulatory effect of a cationic antimicrobial peptide (KLKL5KLK) and a synthetic ODN containing deoxyInosine/deoxy-Cytosine (ODN1a) but not CpG motifs [189]. Apart from the TRL9 activation, IC31 can provide prolonged antigen exposition periods through the complexation of its two components, forming a depot [190]. A strategic collaboration has been established between Intercell (IC31's proprietary) and PATH Malaria Initiative to evaluate the immunological responses to malaria recombinant antigens in combination with IC31 adjuvant.

\subsection{Other Adjuvants in Development}

3.5.1. CoVaccine HT. Synthetic carbohydrates comprising polysaccharides plus lipidic and sulphate groups have demonstrated an interesting immunopotentiation capacity [191]. CoVaccine HT is an o/w emulsion-based vaccine adjuvant consisting of synthetic sucrose fatty acid sulphate esters immobilised inside the oily droplets of the submicron squalane in water emulsion [192]. In accordance with other adjuvants mimicking LPS, the adjuvanticity of CoVaccine HT is mediated through TLR4 signaling, but other mechanisms are also involved since it interacts with DCs independently of binding to TLR4 [193].

Different AMA-1 candidates formulated in CoVaccine HT have been tested in macaques. These candidates improved the antibody secretion and their functionality comparing to Montanide ISA 51 [194], and they also elicited protection after challenge [195]. CoVaccine HT is currently under clinical trials, given alone in healthy volunteers for dose escalation studies and in patients for the development of two therapeutic vaccines (angiotensin therapeutic vaccine and prostate cancer). Importantly, CoVaccine HT's manufacturing is a scalable process that can be done following GMPs.

3.5.2. 7DW8-5 Galcer. Alpha-galactosylceramide ( $\alpha$ GalCer), a glycolipid composed of $\alpha$-linked sugar and lipid moieties, is a well-known ligand that binds CD1d, an MHC class I molecule expressed in most monocytes, macrophages, DCs, and B cells and that it is recognized by invariant NK $\mathrm{T}$ (iNKT) cells [196]. Upon recognition, $\alpha$-GalCer activates iNKT cells to produce Th1 (IFN- $\gamma$ ) and Th2 cytokines (IL-4), which, in turn, activates immune cells including DCs, NKs, 
B cells, and $\mathrm{CD}^{+}$and $\mathrm{CD}^{+} \mathrm{T}$ cells [197]. $\alpha$-GalCer has evidenced raised immunogenicity and efficacy in preclinical vaccines against several infections [196], including malaria, for which enhanced specific $\mathrm{CD} 8^{+} \mathrm{T}$ cell responses and protective immunity were reported [198].

Several analogues of $\alpha$-GalCer with different Th1/Th2 patterns have been developed. Nowadays, 7DW8-5 has emerged as the most important $\alpha$-GalCer derivate compound, which has demonstrated the strongest adjuvanticity (notably increased for $\mathrm{T}$ cell responses but less pronounced for humoral ones) and protective immunity in adenovirusbased HIV and malaria vaccines in murine models [197, 199]. Although glycolipid compounds have progressed to clinical phase as immunotherapeutics for the treatment of cancer and hepatitis B and C, they are not licensed as vaccine adjuvants yet. Nevertheless, they have some benefits such as they allow vaccine dose-sparing and a relative nonexpensive manufacturing process [199].

3.5.3. AFCO1 and AFPL1. AFPL1 is a detergent-extracted outer membrane vesicle (proteoliposome (PL)) of N. meningitidis $B$, and AFCO1 is a particulate derivative presenting multilayer tubular structure. Both AFPL1 and AFCO1 act as delivery systems and have inherent adjuvant capacities (immunopotentiation and immunomodulation). In fact, they contain meningococcal protective antigens (LPS and porins) and allow the packaging of other antigens and PAMPs [200]. Although the antigen can be incorporated during the manufacturing process, their simple coadministration with antigens has also been successfully performed.

AFCO1 has been used in malaria immunization studies with MSP antigens. It induced strong antibody and T cell responses, comparable to CFA, and stimulated the release of specific cytophilic antibodies, IFN $-\gamma$ and $\mathrm{CD}^{+}{ }^{+}$and $\mathrm{CD} 8^{+} \mathrm{T}$ cell proliferation [201], which is in accordance with previously reported Thl polarization.

\section{Perspectives and Final Conclusions}

Currently there is a greater awareness of using suitable adjuvants to develop new effective vaccines. However, there is still a tendency to employ the few approved ones with the wrong intention to rapidly progress to clinical stage. In the case of malaria, a protective vaccine requires antigen-specific $\mathrm{B}$ and $\mathrm{T}$ helper cell responses, CTL responses, and long-lasting B and T memory cell production. Conventional adjuvants such as Alum cannot induce the immune response needed, and there is not a scientific basis for undergoing clinical trials with those adjuvants. Several reasons can lead to the widespread use of traditional adjuvants; sometimes researchers cannot properly formulate their discovered antigens, or they find difficulties to access to the novel adjuvants. On the other hand, regulatory authorities such as FDA do not approve adjuvants as a product alone, but as a part of a vaccine formulation comprising a determined combination of antigen(s) plus adjuvant(s). Each antigen/adjuvant combination requires a complete product development, which restrains the progression of those adjuvants for new vaccine applications [78]. Fortunately, several initiatives have been created during the last years with the aim to promote, rationalize, unify and share the efforts dedicated to the research on new adjuvants [202].

It is essential to know how adjuvants work in order to determine their role in vaccine formulations and to design successful vaccines. The recent advances for clarifying the immune pathways involved in the modulation of the host protective immune response have led to a better understanding of the immunological mechanisms of adjuvants. For instance, new insights on Alum adjuvanticity have been described more than 80 years after its approval. Furthermore, these steps forward have also promoted the discovery of new improved adjuvants.

One of the greatest progresses corresponds to the discovery of TLRs and other innate receptors with the capacity to link innate and adaptive immunity, resulting in the development of a new generation of adjuvants. Besides, the better knowledge of the molecular structure of TLRs is allowing their substitution by synthetic analogues, overcoming some of the concerns related to their potency, toxicity, and manufacturing problems. In addition, other non-TLR PAMPs with potential as vaccine adjuvants have also been discovered, such as RIG-I-like receptors (RLRs), NOD-like receptors (NLRs), and C-type lectin receptors (CLRs).

On the other hand, it is being assumed that a single adjuvant is not enough to elicit protective immunity against certain infectious diseases, such as malaria, which require pluripotent immune responses, adapted to the pathogen and to the targeted population. The combination of multiple adjuvants with different mechanisms of action has been proposed to modulate the interaction between the innate and the adaptive responses. Moreover, the effectiveness of the adjuvant combinations should be based on a synergy between immune response enhancers and delivery systems. The most successful novel combination up to date corresponds to AS formulations. In fact, AS04 enhances humoral and cellular responses [94]; AS02 has yielded 32\% of protection in malaria field clinical trials using the RTS,S antigen [102]; AS01 has improved AS02's response demonstrating stronger humoral and cell-mediated responses, and enhanced protection against malaria [100]. Other TLR combinations have also exhibited high immunogenicity. For example, the combination of TLR $3 / 4$ with TLR7/8/9 increases Th1 CD $4^{+} \mathrm{T}$ cell priming [203]; the mixture of TLR3 plus TLR9 develops specific $\mathrm{CD}^{+} \mathrm{T}$ cell responses [204]; and TLR5 combined with TLR9 elicits more balanced Th1/Th2 responses against extracellular pathogens [205].

As it has been mentioned before, TLRs can be administered included into a particulate vaccine delivery system. For example, microparticles containing TLR4 ligands produce superior immune responses than immunopotentiators administered in solution [206], and microparticles coated with TLR3 agonist (polyI:C) induce DCs maturation [207].

Despite the difficulties regarding both immunological and socioeconomic aspects that malaria eradication arouses, promising results have been achieved during last decade, like a diminution of the mortality by $25 \%$ between 2000 and 2010 [208]. A malaria vaccine could represent a key costeffective intervention for this purpose. RTS,S/AS01, the most 
advanced candidate, achieves protective efficacy in children ranging $30-50 \%[2,3]$ and it is believed that it will represent the first-generation malaria vaccine (WHO recommendation expected by 2015). Nevertheless, it would be still necessary to develop a second-generation vaccine showing improved efficacy (at least 75\%). Thus, malaria vaccines' efficacy could be successfully improved by new combinations of the existing adjuvants with the novel ones, developed based on emerging immunological targets.

\section{Acknowledgments}

This project was partially supported by the "Ministerio de Ciencia e Innovación" (SAF2007-66115), the University of the Basque Country (UPV/EHU) (UFI 11/32), and FEDER funds. E. Mata thanks the Basque Government for a fellowship grant.

\section{References}

[1] M. P. Girard, Z. H. Reed, M. Friede, and M. P. Kieny, "A review of human vaccine research and development: malaria," Vaccine, vol. 25, no. 9, pp. 1567-1580, 2007.

[2] P. Aide, J. J. Aponte, M. Renom et al., "Safety, immunogenicity and duration of protection of the RTS,S/ASO2D malaria vaccine: one year follow-up of a randomized controlled phase I/IIb trial," PLoS ONE, vol. 5, no. 11, Article ID e13838, 2010.

[3] S. T. Agnandji, B. Lell, J. F. Fernandes et al., "A phase 3 trial of RTS,S/AS01 malaria vaccine in African infants," New England Journal of Medicine, vol. 367, no. 24, pp. 2284-2295, 2012.

[4] E. De Gregorio, E. Tritto, and R. Rappuoli, "Alum adjuvanticity: unraveling a century old mystery," European Journal of Immunology, vol. 38, no. 8, pp. 2068-2071, 2008.

[5] N. W. Baylor, W. Egan, and P. Richman, "Aluminum salts in vaccines-US perspective," Vaccine, vol. 20, no. 3, pp. S18-S23, 2002.

[6] J. M. Brewer, M. Conacher, C. A. Hunter, M. Mohrs, F. Brombacher, and J. Alexander, "Aluminium hydroxide adjuvant initiates strong antigen-specific Th2 responses in the absence of IL-4- or IL-13-mediated signaling," Journal of Immunology, vol. 163, no. 12, pp. 6448-6454, 1999.

[7] M. Kool, T. Soullié, M. Van Nimwegen et al., "Alum adjuvant boosts adaptive immunity by inducing uric acid and activating inflammatory dendritic cells," Journal of Experimental Medicine, vol. 205, no. 4, pp. 869-882, 2008.

[8] A. T. Glenny, A. H. Buttle, and M. F. Stevens, "Rate of disappearance of diphtheria toxoid injected into rabbits and guinea pigs: toxoid precipitated with alum," Journal of Pathology and Bacteriology, vol. 34, pp. 267-275, 1932.

[9] L. B. Holt, Developments in Diphtheria Prophylaxis, W. Heinemann, 1950.

[10] R. K. Gupta, A. C. Chang, P. Griffin, R. Rivera, and G. Siber, "In vivo distribution of radioactivity in mice after injection of biodegradable polymer microspheres containing 14C-labeled tetanus toxoid," Vaccine, vol. 14, pp. 1412-1416, 1996.

[11] R. P. Weissburg, P. W. Berman, J. L. Cleland et al., "Characterization of the MN gp120 HIV-1 vaccine: antigen binding to alum," Pharmaceutical Research, vol. 12, pp. 1439-1446, 1995.

[12] J. W. Mannhalter, H. O. Neychev, G. J. Zlabinger, R. Ahmad, and M. M. Eibl, "Modulation of the human immune response by the non-toxic and non-pyrogenic adjuvant aluminium hydroxide: effect on antigen uptake and antigen presentation," Clinical and Experimental Immunology, vol. 61, no. 1, pp. 143-151, 1985.

[13] G. L. Morefield, A. Sokolovska, D. Jiang, H. Hogenesch, J. P. Robinson, and S. L. Hem, "Role of aluminum-containing adjuvants in antigen internalization by dendritic cells in vitro," Vaccine, vol. 23, no. 13, pp. 1588-1595, 2005.

[14] M. Ulanova, A. Tarkowski, M. Hahn-Zoric, and L. Å. Hanson, "The common vaccine adjuvant aluminum hydroxide upregulates accessory properties of human monocytes via an interleukin-4-dependent mechanism," Infection and Immunity, vol. 69, no. 2, pp. 1151-1159, 2001.

[15] A. C. Rimaniol, G. Gras, F. Verdier et al., "Aluminum hydroxide adjuvant induces macrophage differentiation towards a specialized antigen-presenting cell type," Vaccine, vol. 22, no. 23-24, pp. 3127-3135, 2004.

[16] M. B. Jordan, D. M. Mills, J. Kappler, P. Marrack, and J. C. Cambier, "Promotion of B cell immune responses via an aluminduced myeloid cell population," Science, vol. 304, no. 5678, pp. 1808-1810, 2004.

[17] S. C. Eisenbarth, O. R. Colegio, W. O’Connor, F. S. Sutterwala, and R. A. Flavell, "Crucial role for the Nalp3 inflammasome in the immunostimulatory properties of aluminium adjuvants," Nature, vol. 453, no. 7198, pp. 1122-1126, 2008.

[18] M. Kool, V. Pétrilli, T. De Smedt et al., "Cutting edge: alum adjuvant stimulates inflammatory dendritic cells through activation of the NALP3 inflammasome," Journal of Immunology, vol. 181, no. 6, pp. 3755-3759, 2008.

[19] L. Franchi and G. Núñez, "The Nlrp3 inflammasome is critical for aluminum hydroxide-mediated IL- $1 \beta$ secretion but dispensable for adjuvant activity," European Journal of Immunology, vol. 38, no. 8, pp. 2085-2089, 2008.

[20] A. S. McKee, M. W. Munks, M. K. L. MacLeod et al., "Alum induces innate immune responses through macrophage and mast cell sensors, but these sensors are not required for alum to act as an adjuvant for specific immunity," Journal of Immunology, vol. 183, no. 7, pp. 4403-4414, 2009.

[21] M. E. Patarroyo, R. Amador, P. Clavijo et al., "A synthetic vaccine protects humans against challenge with asexual blood stages of Plasmodium falciparum malaria," Nature, vol. 332, no. 6160, pp. 158-161, 1988.

[22] P. Graves and H. Gelband, "Vaccines for preventing malaria (SPf66)," Cochrane Database of Systematic Reviews, no. 2, Article ID CD005966, 2006.

[23] J. A. López, C. Weilenman, R. Audran et al., "A synthetic malaria vaccine elicits a potent $\mathrm{CD} 8^{+}$and $\mathrm{CD} 4^{+} \mathrm{T}$ lymphocyte immune response in humans. Implications for vaccination strategies," European Journal of Immunology, vol. 31, no. 7, pp. 1989-1998, 2001.

[24] R. D. Ellis, L. B. Martin, D. Shaffer et al., "Phase 1 trial of the Plasmodium falciparum blood stage vaccine MSP1(42)C1/Alhydrogel with and without CPG 7909 in malaria naïe adults," PloS ONE, vol. 5, no. 1, article e8787, 2010.

[25] M. Roestenberg, E. Remarque, E. de Jonge et al., "Safety and immunogenicity of a recombinant Plasmodium falciparum AMA1 malaria vaccine adjuvanted with AlhydrogelÜ, Montanide ISA 720 or AS02," PLoS ONE, vol. 3, no. 12, Article ID e3960, 2008.

[26] I. Sagara, A. Dicko, R. D. Ellis et al., "A randomized controlled phase 2 trial of the blood stage AMA1-C1/Alhydrogel malaria vaccine in children in Mali," Vaccine, vol. 27, no. 23, pp. 30903098, 2009. 
[27] C. C. Hermsen, D. F. Verhage, D. S. C. Telgt et al., "Glutamaterich protein (GLURP) induces antibodies that inhibit in vitro growth of Plasmodium falciparum in a phase 1 malaria vaccine trial," Vaccine, vol. 25, no. 15, pp. 2930-2940, 2007.

[28] H. M. El Sahly, S. M. Patel, R. L. Atmar et al., "Safety and immunogenicity of a recombinant nonglycosylated erythrocyte binding antigen 175 region II malaria vaccine in healthy adults living in an area where malaria is not endemic," Clinical and Vaccine Immunology, vol. 17, no. 10, pp. 1552-1559, 2010.

[29] R. Audran, M. Cachat, F. Lurati et al., "Phase I malaria vaccine trial with a long synthetic peptide derived from the merozoite surface protein 3 antigen," Infection and Immunity, vol. 73, no. 12, pp. 8017-8026, 2005.

[30] J. P. Lusingu, S. Gesase, S. Msham et al., "Satisfactory safety and immunogenicity of MSP3 malaria vaccine candidate in Tanzanian children aged 12-24 months," Malaria Journal, vol. 8, no. 1, article 163, 2009.

[31] M. Esen, P. G. Kremsner, R. Schleucher et al., "Safety and immunogenicity of GMZ2-a MSP3-GLURP fusion protein malaria vaccine candidate," Vaccine, vol. 27 , no. 49 , pp. $6862-$ $6868,2009$.

[32] T. Horii, H. Shirai, L. Jie et al., "Evidences of protection against blood-stage infection of Plasmodium falciparum by the novel protein vaccine SE36," Parasitology International, vol. 59, no. 3, pp. 380-386, 2010.

[33] D. C. Kaslow, “Transmission-blocking vaccines," Chemical Immunology, vol. 80, pp. 287-307, 2002.

[34] E. M. Malkin, A. P. Durbin, D. J. Diemert et al., "Phase 1 vaccine trial of Pvs25H: a transmission blocking vaccine for Plasmodium vivax malaria," Vaccine, vol. 23, no. 24, pp. 31313138, 2005.

[35] "Initial study of Malaria Vaccine PFs25-EPA/Alhydrogel," 2012, http://www.clinicaltrials.gov/ct2/show/NCT01434381.

[36] F. Qian, Y. Wu, O. Muratova et al., "Conjugating recombinant proteins to Pseudomonas aeruginosa ExoProtein A: a strategy for enhancing immunogenicity of malaria vaccine candidates," Vaccine, vol. 25, no. 20, pp. 3923-3933, 2007.

[37] G. Ott, G. L. Barchfeld, D. Chernoff, R. Radhakrishnan, P. van Hoogevest, and G. Van Nest, "MF59. Design and evaluation of a safe and potent adjuvant for human vaccines," Pharmaceutical biotechnology, vol. 6, pp. 277-296, 1995.

[38] A. Wack, B. C. Baudner, A. K. Hilbert et al., "Combination adjuvants for the induction of potent, long-lasting antibody and T-cell responses to influenza vaccine in mice," Vaccine, vol. 26, no. 4, pp. 552-561, 2008.

[39] G. Corradin and G. Del Giudice, "Novel adjuvants for vaccines," Current Medicinal Chemistry, vol. 4, no. 2, pp. 185-191, 2005.

[40] A. Seubert, E. Monaci, M. Pizza, D. T. O'hagan, and A. Wack, "The adjuvants aluminum hydroxide and MF59 induce monocyte and granulocyte chemoattractants and enhance monocyte differentiation toward dendritic cellsl," Journal of Immunology, vol. 180, no. 8, pp. 5402-5412, 2008.

[41] S. S. Yazdani, A. R. Shakri, P. Mukherjee, S. K. Baniwal, and C. E. Chitnis, "Evaluation of immune responses elicited in mice against a recombinant malaria vaccine based on Plasmodium vivax Duffy binding protein," Vaccine, vol. 22, no. 27-28, pp. 3727-3737, 2004.

[42] S. Sachdeva, A. Mohmmed, P. V. N. Dasaradhi et al., "Immunogenicity and protective efficacy of Escherichia coli expressed Plasmodium falciparum merozoite surface protein-142 using human compatible adjuvants," Vaccine, vol. 24, no. 12, pp. 20072016, 2006.
[43] A. W. Stowers, V. Cioce, R. L. Shimp et al., "Efficacy of two alternate vaccines based on Plasmodium falciparum merozoite surface protein 1 in an Aotus challenge trial," Infection and Immunity, vol. 69, no. 3, pp. 1536-1546, 2001.

[44] J. Inselburg, I. C. Bathurst, J. Kansopon, P. J. Barr, and R. Rossan, "Protective immunity induced in Aotus monkeys by a recombinant SERA protein of Plasmodium falciparum: further studies using SERA 1 and MF75.2 adjuvant," Infection and Immunity, vol. 61, no. 5, pp. 2048-2052, 1993.

[45] F. Roman, F. Clément, W. Dewé et al., "Effect on cellular and humoral immune responses of the AS03 adjuvant system in an $\mathrm{A} / \mathrm{H} 1 \mathrm{N1} / 2009$ influenza virus vaccine administered to adults during two randomized controlled trials," Clinical and Vaccine Immunology, vol. 18, no. 5, pp. 835-843, 2011.

[46] S. Morel, A. Didierlaurent, P. Bourguignon et al., "Adjuvant System AS03 containing $\alpha$-tocopherol modulates innate immune response and leads to improved adaptive immunity," Vaccine, vol. 29, no. 13, pp. 2461-2473, 2011.

[47] E. Mohr, K. Serre, R. A. Manz et al., "Dendritic cells and monocyte/macrophages that create the IL-6/APRIL-rich lymph node microenvironments where plasmablasts mature," Journal of Immunology, vol. 182, no. 4, pp. 2113-2123, 2009.

[48] J. A. Stoute, M. Slaoui, D. G. Heppner et al., "A preliminary evaluation of a recombinant circumsporozoite protein vaccine against Plasmodium falciparum malaria," New England Journal of Medicine, vol. 336, no. 2, pp. 86-91, 1997.

[49] J. Aucouturier, L. Dupuis, S. Deville, S. Ascarateil, and V. Ganne, "Montanide ISA 720 and 51: a new generation of water in oil emulsions as adjuvants for human vaccines," Expert Review of Vaccines, vol. 1, no. 1, pp. 111-118, 2002.

[50] L. Benmohamed, A. Thomas, M. Bossus et al., "High immunogenicity in chimpanzees of peptides and lipopeptides derived from four new Plasmodium falciparum pre-erythrocytic molecules," Vaccine, vol. 18, no. 25, pp. 2843-2855, 2000.

[51] J. Aucouturier, L. Dupuis, and V. Ganne, "Adjuvants designed for veterinary and human vaccines," Vaccine, vol. 19, no. 17-19, pp. 2666-2672, 2001.

[52] B. Genton, V. D’Acremont, F. Lurati-Ruiz et al., "Randomized double-blind controlled Phase I/IIa trial to assess the efficacy of malaria vaccine PfCS102 to protect against challenge with $P$. falciparum," Vaccine, vol. 28, no. 40, pp. 6573-6580, 2010.

[53] P. Daubersies, B. Ollomo, J. P. Sauzet et al., "Genetic immunisation by liver stage antigen 3 protects chimpanzees against malaria despite low immune responses," PLOS ONE, vol. 3, no. 7, Article ID e2659, 2008.

[54] B. Genton, F. Al-Yaman, I. Betuela et al., "Safety and immunogenicity of a three-component blood-stage malaria vaccine (MSP1, MSP2, RESA) against Plasmodium falciparum in Papua New Guinean children," Vaccine, vol. 22, no. 1, pp. 30-41, 2003.

[55] G. Lawrence, Q. Cheng, C. Reed et al., "Effect of vaccination with 3 recombinant asexual-stage malaria antigens on initial growth rates of Plasmodium falciparum in non-immune volunteers," Vaccine, vol. 18, no. 18, pp. 1925-1931, 2000.

[56] E. Malkin, J. Hu, Z. Li et al., "A Phase 1 trial of PfCP2.9: an AMA1/MSP1 chimeric recombinant protein vaccine for Plasmodium falciparum malaria," Vaccine, vol. 26, no. 52, pp. 6864-6873, 2008.

[57] M. A. Pierce, R. D. Ellis, L. B. Martin et al., "Phase 1 safety and immunogenicity trial of the Plasmodium falciparum bloodstage malaria vaccine AMA1-C1/ISA 720 in Australian adults," Vaccine, vol. 28, no. 10, pp. 2236-2242, 2010. 
[58] J. S. McCarthy, J. Marjason, S. Elliott et al., "A phase 1 trial of a bivalent MSP2 blod-stage malaria vaccine formulated with Montanide ISA 720," in Abstracts Book of the American Society of Tropical Medicine and Hygiene 57th Annual Meeting, vol. 1076, 2008.

[59] Y. Wu, R. D. Ellis, D. Shaffer et al., "Phase 1 trial of malaria transmission blocking vaccine candidates Pfs 25 and Pvs 25 formulated with montanide ISA 51," PLoS ONE, vol. 3, no. 7, Article ID e2636, 2008.

[60] B. C. Carlson, A. M. Jansson, A. Larsson, A. Bucht, and J. C. Lorentzen, "The endogenous adjuvant squalene can induce a chronic T-cell-mediated arthritis in rats," American Journal of Pathology, vol. 156, no. 6, pp. 2057-2065, 2000.

[61] H. X. Sun, Y. Xie, and Y. P. Ye, "Advances in saponin-based adjuvants," Vaccine, vol. 27, no. 12, pp. 1787-1796, 2009.

[62] K. Dalsgaard, "A study of the isolation and characterization of the saponin Quil A. Evaluation of its adjuvant activity, with a special reference to the application in the vaccination of cattle against foot-and-mouth disease," Acta veterinaria Scandinavica, no. 69, pp. 7-40, 1978.

[63] D. C. Waite, E. W. Jacobson, F. A. Ennis et al., "Three doubleblind, randomized trials evaluating the safety and tolerance of different formulations of the saponin adjuvant QS-21," Vaccine, vol. 19, no. 28-29, pp. 3957-3967, 2001.

[64] Z. I. Rajput, S. H. Hu, C. W. Xiao, and A. G. Arijo, "Adjuvant effects of saponins on animal immune responses," Journal of Zhejiang University. Science B, vol. 8, no. 3, pp. 153-161, 2007.

[65] A. M. Glauert, J. T. Dingle, and J. A. Lucy, "Action of saponin on biological cell membranes," Nature, vol. 196, no. 4858, pp. 953955, 1962.

[66] O. Kashala, R. Amador, M. V. Valero et al., "Safety, tolerability and immunogenicity of new formulations of the Plasmodium falciparum malaria peptide vaccine SPf66 combined with the immunological adjuvant QS-21," Vaccine, vol. 20, no. 17-18, pp. 2263-2277, 2002.

[67] G. F. A. Kersten and D. J. A. Crommelin, "Liposomes and ISCOMs," Vaccine, vol. 21, no. 9-10, pp. 915-920, 2003.

[68] A. Coulter, R. Harris, R. Davis et al., "Intranasal vaccination with ISCOMATRIX adjuvanted influenza vaccine," Vaccine, vol. 21, no. 9-10, pp. 946-949, 2003.

[69] M. J. Pearse and D. Drane, "ISCOMATRIX adjuvant for antigen delivery," Advanced Drug Delivery Reviews, vol. 57, no. 3, pp. 465-474, 2005.

[70] E. Furrie, R. E. Smith, M. W. Turner, S. Strobel, and A. M. Mowat, "Induction of local innate immune responses and modulation of antigen uptake as mechanisms underlying the mucosal adjuvant properties of immune stimulating complexes (ISCOMS)," Vaccine, vol. 20, no. 17-18, pp. 2254-2262, 2002.

[71] M. J. Lockyer, H. Cooper, J. Tite, W. Rowan, and J. S. Crowe, "Immunogenicity of a hybrid Plasmodium falciparum malaria antigen," Parasitology, vol. 106, no. 5, pp. 451-457, 1993.

[72] A. Sjolander, M. Hansson, K. Lovgren, B. Wahlin, K. Berzsins, and P. Perlmann, "Immunogenicity in rabbits and monkeys of influenza ISCOMs conjugated with repeated sequences of the Plasmodium falciparum antigen Pf155/RESA," Parasite Immunology, vol. 15, no. 6, pp. 355-359, 1993.

[73] N. Chopra, S. Biswas, B. Thomas, L. Sabhnani, and D. N. Rao, "Inducing protective antibodies against ring-infected erythrocyte surface peptide antigen of Plasmodium falciparum using immunostimulating complex (ISCOMS) delivery," Medical Microbiology and Immunology, vol. 189, no. 2, pp. 75-83, 2000 .
[74] V. Meraldi, J. F. Romero, C. Kensil, and G. Corradin, "A strong $\mathrm{CD}^{+} \mathrm{T}$ cell response is elicited using the synthetic polypeptide from the C-terminus of the circumsporozoite protein of Plasmodium berghei together with the adjuvant QS21: quantitative and phenotypic comparison with the vaccine model of irradiated sporozoites," Vaccine, vol. 23, no. 21, pp. 2801-2812, 2005

[75] E. V. L. Grgacic and D. A. Anderson, "Virus-like particles: passport to immune recognition," Methods, vol. 40, no. 1, pp. 60-65, 2006.

[76] T. M. Kündig, G. Senti, G. Schnetzler et al., "Der $\mathrm{p} 1$ peptide on virus-like particles is safe and highly immunogenic in healthy adults," Journal of Allergy and Clinical Immunology, vol. 117, no. 6, pp. 1470-1476, 2006.

[77] J. F. Roth, “The yeast Ty virus-like particles," Yeast, vol. 16, no. 9, pp. 785-795, 2000.

[78] S. G. Reed, S. Bertholet, R. N. Coler, and M. Friede, "New horizons in adjuvants for vaccine development," Trends in Immunology, vol. 30, no. 1, pp. 23-32, 2009.

[79] A. L. Gregson, G. Oliveira, C. Othoro et al., "Phase I trial of an Alhydrogel adjuvanted hepatitis B core virus-like particle containing epitopes of Plasmodium falciparum circumsporozoite protein," PLoS ONE, vol. 3, no. 2, Article ID e1556, 2008.

[80] M. Walther, S. Dunachie, S. Keating et al., "Safety, immunogenicity and efficacy of a pre-erythrocytic malaria candidate vaccine, ICC-1132 formulated in Seppic ISA 720," Vaccine, vol. 23, no. 7, pp. 857-864, 2005.

[81] D. M. Gordon, T. W. McGovern, U. Krzych et al., "Safety, immunogenicity, and efficacy of a recombinantly produced Plasmodium falciparum circumsporozoite protein-hepatitis B surface antigen subunit vaccine," Journal of Infectious Diseases, vol. 171, no. 6, pp. 1576-1585, 1995.

[82] D. M. Da Silva, D. V. Pastrana, J. T. Schiller, and W. M. Kast, "Effect of preexisting neutralizing antibodies on the anti-tumor immune response induced by chimeric human papillomavirus virus-like particle vaccines," Virology, vol. 290, no. 2, pp. 350 360, 2001.

[83] K. Takeda and S. Akira, "Toll-like receptors in innate immunity," International Immunology, vol. 17, no. 1, pp. 1-14, 2005.

[84] R. Medzhitov and C. Janeway Jr., "Advances in immunology: innate immunity," New England Journal of Medicine, vol. 343, no. 5, pp. 338-344, 2000.

[85] R. Medzhitov, "Toll-like receptors and innate immunity," Nature Reviews Immunology, vol. 1, no. 2, pp. 135-145, 2001.

[86] Y. Kumagai and S. Akira, "Identification and functions of pattern-recognition receptors," Journal of Allergy and Clinical Immunology, vol. 125, no. 5, pp. 985-992, 2010.

[87] L. A. J. O’Neill and A. G. Bowie, “The family of five: TIRdomain-containing adaptors in Toll-like receptor signalling," Nature Reviews Immunology, vol. 7, no. 5, pp. 353-364, 2007.

[88] H. Kumar, T. Kawai, and S. Akira, "Toll-like receptors and innate immunity," Biochemical and Biophysical Research Communications, vol. 388, no. 4, pp. 621-625, 2009.

[89] M. Hedayat, M. G. Netea, and N. Rezaei, “Targeting of Tolllike receptors: a decade of progress in combating infectious diseases," Lancet Infectious Diseases, vol. 11, no. 9, pp. 702-712, 2011.

[90] A. Lahiri, P. Das, and D. Chakravortty, "Engagement of TLR signaling as adjuvant: towards smarter vaccine and beyond," Vaccine, vol. 26, no. 52, pp. 6777-6783, 2008. 
[91] C. Pasare and R. Medzhitov, "Toll-like receptors: linking innate and adaptive immunity," Microbes and Infection, vol. 6, no. 15, pp. 1382-1387, 2004.

[92] S. Casares, T. D. Brumeanu, and T. L. Richie, “The RTS,S malaria vaccine," Vaccine, vol. 28, no. 31, pp. 4880-4894, 2010.

[93] J. Beran, "Safety and immunogenicity of a new hepatitis B vaccine for the protection of patients with renal insufficiency including pre-haemodialysis and haemodialysis patients," Expert Opinion on Biological Therapy, vol. 8, no. 2, pp. 235-247, 2008.

[94] G. Leroux-Rouls, E. Moreaux, and I. Desombre, "Persistence of humoral and cellular immune response and booster effect following vaccination with herpes simplex $(\mathrm{gD} 2 \mathrm{t})$ candidate vaccine with MPL," in Abstracts of the 34th Interscience Conference on Antimicrobial Agents and Chemotherapy, p. 205, American Society for Microbiology, Washington, DC, USA, 1994.

[95] C. L. Tielemans, J. Vlasak, D. Kosa et al., "Immunogenicity and safety of an investigational AS02v-adjuvanted hepatitis $B$ vaccine in patients with renal insufficiency who failed to respond or to maintain antibody levels after prior vaccination: results of two open, randomized, comparative trials," Vaccine, vol. 29, no. 6, pp. 1159-1166, 2011.

[96] P. Denoël, M. T. Philipp, L. Doyle, D. Martin, G. Carletti, and J. T. Poolman, "A protein-based pneumococcal vaccine protects rhesus macaques from pneumonia after experimental infection with Streptococcus pneumoniae," Vaccine, vol. 29, no. 33, pp. 5495-5501, 2011.

[97] C. W. Cluff, "Monophosphoryl lipid a (MPL) as an adjuvant for anti-cancer vaccines: clinical results," Advances in Experimental Medicine and Biology, vol. 667, pp. 111-123, 2010.

[98] R. Audran, F. Lurati-Ruiz, B. Genton et al., "The synthetic Plasmodium falciparum circumsporozoite peptide PfCS102 as a malaria vaccine candidate: a randomized controlled phase I trial," PLoS ONE, vol. 4, no. 10, Article ID e7304, 2009.

[99] J. F. Cummings, M. D. Spring, R. J. Schwenk et al., "Recombinant Liver Stage Antigen-1 (LSA-1) formulated with AS01 or AS02 is safe, elicits high titer antibody and induces IFN$\gamma / \mathrm{IL}-2 \mathrm{CD} 4+\mathrm{T}$ cells but does not protect against experimental Plasmodium falciparum infection," Vaccine, vol. 28, no. 31, pp. 5135-5144, 2010.

[100] K. E. Kester, J. F. Cummings, O. Ofori-Anyinam et al., "Randomized, double-blind, phase $2 \mathrm{a}$ trial of falciparum malaria vaccines RTS,S/AS01B and RTS,S/AS02A in malaria-naive adults: safety, efficacy, and immunologic associates of protection," Journal of Infectious Diseases, vol. 200, no. 3, pp. 337-346, 2009.

[101] K. A. Bojang, P. J. M. Milligan, M. Pinder et al., "Efficacy of RTS,S/AS02 malaria vaccine against Plasmodium falciparum infection in semi-immune adult men in The Gambia: a randomised trial," Lancet, vol. 358, no. 9297, pp. 1927-1934, 2001.

[102] M. E. Polhemus, S. A. Remich, B. R. Ogutu et al., "Evaluation of RTS,S/AS02A and RTS,S/AS01B in adults in a high malaria transmission area," PLoS ONE, vol. 4, no. 7, Article ID e6465, 2009.

[103] J. Sacarlal, P. Aide, J. J. Aponte et al., "Long-term safety and efficacy of the RTS,S/AS02A malaria vaccine in mozambican children," Journal of Infectious Diseases, vol. 200, no. 3, pp. 329336, 2009.

[104] J. J. Aponte, P. Aide, M. Renom et al., "Safety of the RTS,S/AS02D candidate malaria vaccine in infants living in a highly endemic area of Mozambique: a double blind randomised controlled phase I/IIb trial," Lancet, vol. 370, no. 9598, pp. 1543-1551, 2007.

[105] B. R. Ogutu, O. J. Apollo, D. McKinney et al., "Blood stage malaria vaccine eliciting high antigen-specific antibody concentrations confers no protection to young children in Western Kenya," PLoS ONE, vol. 4, no. 3, Article ID e4708, 2009.

[106] M. A. Thera, O. K. Doumbo, D. Coulibaly et al., "Safety and immunogenicity of an AMA1 malaria vaccine in Malian children: results of a phase 1 randomized controlled trial," PLOS ONE, vol. 5, no. 2, Article ID e9041, 2010.

[107] M. D. Spring, J. F. Cummings, C. F. Ockenhouse et al., "Phase $1 / 2$ a study of the malaria vaccine candidate apical membrane antigen-1 (AMA-l) administered in adjuvant system AS01B or AS02A," PLoS ONE, vol. 4, no. 4, Article ID e5254, 2009.

[108] S. Forgus, I. Leroux-Roels, F. De Boeve et al., "Safety and immunogenicity of the M72/AS01B and M72/AS02A candidate tuberculosis vaccines in PPD-negative Belgian adults," in TBV 2008-TB Vaccines For the World, 2008.

[109] E. Van Braeckel, P. Bourguignon, M. Koutsoukos et al., "An adjuvanted polyprotein HIV-1 vaccine induces polyfunctional cross-reactive $\mathrm{CD} 4^{+} \mathrm{T}$ cell responses in seronegative volunteers," Clinical Infectious Diseases, vol. 52, no. 4, pp. 522-531, 2011.

[110] P. Mettens, P. M. Dubois, M. A. Demoitié et al., "Improved T cell responses to Plasmodium falciparum circumsporozoite protein in mice and monkeys induced by a novel formulation of RTS,S vaccine antigen," Vaccine, vol. 26, no. 8, pp. 1072-1082, 2008.

[111] J. P. Shott, S. M. McGrath, M. G. Pau et al., "Adenovirus 5 and 35 vectors expressing Plasmodium falciparum circumsporozoite surface protein elicit potent antigen-specific cellular IFN- $\gamma$ and antibody responses in mice," Vaccine, vol. 26, no. 23, pp. 28182823, 2008.

[112] P. Bejon, J. Lusingu, A. Olotu et al., "Efficacy of RTS,S/AS01E vaccine against malaria in children 5 to 17 months of age," New England Journal of Medicine, vol. 359, no. 24, pp. 2521-2532, 2008.

[113] S. T. Agnandji, B. Lell, S. S. Soulanoudjingar et al., "First results of phase 3 trial of RTS,S/AS01 malaria vaccine in African children," New England Journal of Medicine, vol. 365, no. 20, pp. 1863-1875, 2011.

[114] A. M. Krieg, "CpG motifs in bacterial DNA and their immune effects," Annual Review of Immunology, vol. 20, pp. 709-760, 2002.

[115] A. M. Harandi and J. Holmgren, "CpG DNA as a potent inducer of mucosal immunity: implications for immunoprophylaxis and immunotherapy of mucosal infections," Current Opinion in Investigational Drugs, vol. 5, no. 2, pp. 141-145, 2004.

[116] A. M. Krieg, "Antitumor applications of stimulating Toll-like receptor 9 with CpG oligodeoxynucleotides," Current Oncology Reports, vol. 6, no. 2, pp. 88-95, 2004.

[117] G. K. Gupta and D. K. Agrawal, "CpG oligodeoxynucleotides as TLR9 agonists: therapeutic application in allergy and asthma," BioDrugs, vol. 24, no. 4, pp. 225-235, 2010.

[118] I. Sagara, R. D. Ellis, A. Dicko et al., "A randomized and controlled Phase 1 study of the safety and immunogenicity of the AMA1-C1/Alhydrogel + CPG 7909 vaccine for Plasmodium falciparum malaria in semi-immune Malian adults," Vaccine, vol. 27, no. 52, pp. 7292-7298, 2009. 
[119] B. Traore, Y. Koné, S. Doumbo et al., “The TLR9 agonist CpG fails to enhance the acquisition of Plasmodium falciparumspecific memory B cells in semi-immune adults in Mali," Vaccine, vol. 27, no. 52, pp. 7299-7303, 2009.

[120] R. D. Ellis, Y. Wu, L. B. Martin et al., "Phase 1 study in malaria naive adults of BSAM2/Alhydrogel+CPG 7909, a blood stage vaccine against $P$. falciparum malaria," PLoS One, vol. 7, no. 10, Article ID e46094, 2012.

[121] D. M. Klinman, S. Klaschik, T. Sato, and D. Tross, "CpG oligonucleotides as adjuvants for vaccines targeting infectious diseases," Advanced Drug Delivery Reviews, vol. 61, no. 3, pp. 248-255, 2009.

[122] H. T. Ichikawa, L. P. Williams, and B. M. Segal, "Activation of APCs through CD40 or toll-like receptor 9 overcomes tolerance and precipitates autoimmune disease," Journal of Immunology, vol. 169, no. 5, pp. 2781-2787, 2002.

[123] L. J. Peek, C. R. Middaugh, and C. Berkland, "Nanotechnology in vaccine delivery," Advanced Drug Delivery Reviews, vol. 60, no. 8, pp. 915-928, 2008.

[124] R. Glück, C. Moser, and I. C. Metcalfe, "Influenza virosomes as an efficient system for adjuvanted vaccine delivery," Expert Opinion on Biological Therapy, vol. 4, no. 7, pp. 1139-1145, 2004.

[125] R. Glück, K. G. Burri, and I. Metcalfe, "Adjuvant and antigen delivery properties of virosomes," Current Drug Delivery, vol. 2, no. 4, pp. 395-400, 2005.

[126] K. S. Matlin, H. Reggio, A. Helenius, and K. Simons, "Infectious entry pathway of influenza virus in a canine kidney cell line," Journal of Cell Biology, vol. 91, no. 3, pp. 601-613, 1981.

[127] L. Bungener, A. Huckriede, A. De Mare, J. De Vries-Idema, J. Wilschut, and T. Daemen, "Virosome-mediated delivery of protein antigens in vivo: efficient induction of class I MHCrestricted cytotoxic T lymphocyte activity," Vaccine, vol. 23, no. 10, pp. 1232-1241, 2005.

[128] B. Genton, G. Pluschke, L. Degen et al., "A randomized placebocontrolled phase la malaria vaccine trial of two virosomeformulated synthetic peptides in healthy adult volunteers," PLoS ONE, vol. 2, no. 10, Article ID e1018, 2007.

[129] S. L. Okitsu, O. Silvie, N. Westerfeld et al., "A virosomal malaria Peptide vaccine elicits a longlasting sporozoite-inhibitory antibody response in a phase la clinical trail," PLoS ONE, vol. 2, no. 12, Article ID e1278, 2007.

[130] F. M. Thompson, D. W. Porter, S. L. Okitsu et al., "Evidence of blood stage efficacy with a virosomal malaria vaccine in a phase IIa clinical trial," PLoS ONE, vol. 3, no. 1, Article ID e1493, 2008.

[131] D. R. Cavanagh, E. J. Remarque, R. W. Sauerwein, C. C. Hermsen, and A. J. F. Luty, "Influenza virosomes: a flu jab for malaria?" Trends in Parasitology, vol. 24, no. 9, pp. 382-385, 2008.

[132] A. Brun, E. Albina, T. Barret et al., "Antigen delivery systems for veterinary vaccine development. Viral-vector based delivery systems," Vaccine, vol. 26, no. 51, pp. 6508-6528, 2008.

[133] S. J. Draper and J. L. Heeney, "Viruses as vaccine vectors for infectious diseases and cancer," Nature Reviews Microbiology, vol. 8, no. 1, pp. 62-73, 2010.

[134] C. S. Rollier, A. Reyes-Sandoval, M. G. Cottingham, K. Ewer, and A. V. S. Hill, "Viral vectors as vaccine platforms: deployment in sight," Current Opinion in Immunology, vol. 23, no. 3, pp. 377-382, 2011.

[135] J. S. Lee, A. G. Hadjipanayis, and M. D. Parker, "Viral vectors for use in the development of biodefense vaccines," Advanced Drug Delivery Reviews, vol. 57, no. 9, pp. 1293-1314, 2005.
[136] M. Walther, F. M. Thompson, S. Dunachie et al., "Safety, immunogenicity, and efficacy of prime-boost immunization with recombinant poxvirus FP9 and modified vaccinia virus Ankara encoding the full-length Plasmodium falciparum circumsporozoite protein," Infection and Immunity, vol. 74, no. 5, pp. 2706-2716, 2006.

[137] S. J. Dunachie, M. Walther, J. E. Epstein et al., "A DNA prime-modified vaccinia virus Ankara boost vaccine encoding thrombospondin-related adhesion protein but not circumsporozoite protein partially protects healthy malaria-naive adults against Plasmodium falciparum sporozoite challenge," Infection and Immunity, vol. 74, no. 10, pp. 5933-5942, 2006.

[138] E. B. Imoukhuede, T. Berthoud, P. Milligan et al., "Safety and immunogenicity of the malaria candidate vaccines FP9 CS and MVA CS in adult Gambian men," Vaccine, vol. 24, no. 42-43, pp. 6526-6533, 2006.

[139] J. M. Vuola, S. Keating, D. P. Webster et al., "Differential immunogenicity of various heterologous prime-boost vaccine regimens using DNA and viral vectors in healthy volunteers," Journal of Immunology, vol. 174, no. 1, pp. 449-455, 2005.

[140] P. Bejon, E. Ogada, T. Mwangi et al., "Extended follow-up following a phase $2 \mathrm{~b}$ randomized trial of the candidate malaria vaccines FP9 ME-TRAP and MVA ME-TRAP among children in Kenya," PloS ONE, vol. 2, no. 1, article e707, 2007.

[141] E. Prieur, S. C. Gilbert, J. Schneider et al., "A Plasmodium falciparum candidate vaccine based on a six-antigen polyprotein encoded by recombinant poxviruses," Proceedings of the National Academy of Sciences of the United States of America, vol. 101, no. 1, pp. 290-295, 2004.

[142] D. W. Porter, F. M. Thompson, T. K. Berthoud et al., "A human Phase I/IIa malaria challenge trial of a polyprotein malaria vaccine," Vaccine, vol. 29, no. 43, pp. 7514-7522, 2011.

[143] C. Tamminga, M. Sedegah, D. Regis et al., "Adenovirus-5vectored $P$. falciparum vaccine expressing CSP and AMA1-part B: safety, immunogenicity and protective efficacy of the CSP component," PLoS ONE, vol. 6, no. 10, Article ID e25868, 2011.

[144] S. Li, E. Locke, J. Bruder et al., "Viral vectors for malaria vaccine development," Vaccine, vol. 25, no. 14, pp. 2567-2574, 2007.

[145] V. A. Stewart, S. M. McGrath, P. M. Dubois et al., "Priming with an adenovirus 35-circumsporozoite protein (CS) vaccine followed by RTS,S/AS01B boosting significantly improves immunogenicity to Plasmodium falciparum CS compared to that with either malaria vaccine alone," Infection and Immunity, vol. 75, no. 5, pp. 2283-2290, 2007.

[146] K. Radošević, A. Rodriguez, A. A. C. Lemckert et al., “The Th1 Immune response to Plasmodium falciparum circumsporozoite protein is boosted by adenovirus vectors 35 and 26 with a homologous insert," Clinical and Vaccine Immunology, vol. 17, no. 11, pp. 1687-1694, 2010.

[147] G. A. O. 'Hara, C. J. Duncan, K. J. Ewer et al., "Clinical assessment of a recombinant simian adenovirus ChAd63: a potent new vaccine vector," Journal of Infectious Diseases, vol. 205, no. 5, pp. 772-781, 2012.

[148] "A Phase I/IIa Sporozoite Challenge Study to Assess the Protective Efficacy of Two Prime-Boost Malaria Vaccine Candidates: ChAd63 and MVA Encoding ME-TRAP and the Same Viral Vectors Encoding CS," 2012, http:// clinicaltrialsfeeds.org/clinical trials/show/NCT01623557.

[149] A. Reyes-Sandoval, T. Berthoud, N. Alder et al., "Prime-boost immunization with adenoviral and modified vaccinia virus Ankara vectors enhances the durability and polyfunctionality 
of protective malaria $\mathrm{CD}^{+}$T-cell responses," Infection and Immunity, vol. 78, no. 1, pp. 145-153, 2010.

[150] S. Capone, A. Reyes-Sandoval, M. Naddeo et al., "Immune responses against a liver-stage malaria antigen induced by simian adenoviral vector AdCh63 and MVA prime-boost immunisation in non-human primates," Vaccine, vol. 29, no. 2, pp. 256-265, 2010.

[151] S. H. Sheehy, C. J. Duncan, S. C. Elias et al., "Phase Ia clinical evaluation of the Plasmodium falciparum blood-stage antigen MSP1 in ChAd63 and MVA vaccine vectors," Molecular Therapy, vol. 19, no. 12, pp. 2269-2276, 2011.

[152] S. H. Sheehy, C. J. A. Duncan, S. C. Elias et al., "Phase Ia clinical evaluation of the safety and immunogenicity of the Plasmodium falciparum blood-stage antigen AMA1 in ChAd63 and MVA vaccine vectors," PLoS ONE, vol. 7, no. 2, Article ID e31208, 2012.

[153] S. H. Sheehy, C. J. Duncan, S. C. Elias et al., "ChAd63-MVAvectored blood-stage malaria vaccines targeting MSP1 and AMA1: assessment of efficacy against mosquito bite challenge in humans," Molecular Therapy, vol. 20, no. 12, pp. 2355-2368, 2012.

[154] G. Gregoriadis, "Immunological adjuvants: a role for liposomes," Immunology Today, vol. 11, no. 3, pp. 89-97, 1990.

[155] C. R. Alving, "Liposomes as carriers of antigens and adjuvants," Journal of Immunological Methods, vol. 140, no. 1, pp. 1-13, 1991.

[156] I. Rosenkrands, C. Vingsbo-Lundberg, T. J. Bundgaard et al., "Enhanced humoral and cell-mediated immune responses after immunization with trivalent influenza vaccine adjuvanted with cationic liposomes," Vaccine, vol. 29, no. 37, pp. 6283-6291, 2011.

[157] E. M. Agger, I. Rosenkrands, J. Hansen et al., "Cationic liposomes formulated with synthetic mycobacterial cordfactor (CAF01): a versatile adjuvant for vaccines with different immunological requirements," PLoS ONE, vol. 3, no. 9, Article ID e3116, 2008.

[158] World Health Organization, "Malaria Vaccine Rainbow Tables (Dec 2012)," 2012, http://www.who.int/vaccine_research/links/ Rainbow//en/index.html.

[159] M. N. Ravi Kumar, "Nano and microparticles as controlled drug delivery devices," Journal of Pharmacy \& Pharmaceutical Sciences, vol. 3, no. 2, pp. 234-258, 2000.

[160] S. S. Davis, "The use of soluble polymers and polymer microparticles to provide improved vaccine responses after parenteral and mucosal delivery," Vaccine, vol. 24, no. 2, supplement, pp. S2-S10, 2006.

[161] E. A. McNeela and E. C. Lavelle, "Recent advances in microparticle and nanoparticle delivery vehicles for mucosal vaccination," Current Topics in Microbiology and Immunology, vol. 354, pp. 75-99, 2012.

[162] A. Salvador, M. Igartua, R. M. Hernandez, and J. L. Pedraz, "Combination of immune stimulating adjuvants with poly(lactide-co-glycolide) microspheres enhances the immune response of vaccines," Vaccine, vol. 30, no. 3, pp. 589-596, 2012.

[163] K. Kim and D. Pack, "Microspheres for drug delivery," in BioMEMs and Biomedical Nanotecnohlogy-Volume I: Biological and Biomedical Nanotechnology, pp. 19-49, Springer, 2006.

[164] J. M. Anderson and M. S. Shive, "Biodegradation and biocompatibility of PLA and PLGA microspheres," Advanced Drug Delivery Reviews, vol. 28, no. 1, pp. 5-24, 1997.

[165] W. Wang and M. Singh, "Selection of adjuvants for enhanced vaccine potency," World Journal of Vaccines, vol. 1, pp. 33-78, 2011.
[166] P. Johansen, Y. Men, H. P. Merkle, and B. Gander, "Revisiting PLA/PLGA microspheres: an analysis of their potential in parenteral vaccination," European Journal of Pharmaceutics and Biopharmaceutics, vol. 50, no. 1, pp. 129-146, 2000.

[167] E. Mata, A. M. Carcaboso, R. M. Hernández, M. Igartua, G. Corradin, and J. L. Pedraz, "Adjuvant activity of polymer microparticles and Montanide ISA 720 on immune responses to Plasmodium falciparum MSP2 long synthetic peptides in mice," Vaccine, vol. 25, no. 5, pp. 877-885, 2007.

[168] Y. Men, H. Tamber, R. Audran, B. Gander, and G. Corradin, "Induction of a cytotoxic $\mathrm{T}$ lymphocyte response by immunization with a malaria specific CTL peptide entrapped in biodegradable polymer microspheres," Vaccine, vol. 15, no. 1213, pp. 1405-1412, 1997.

[169] A. M. Carcaboso, R. M. Hernández, M. Igartua, J. E. Rosas, M. E. Patarroyo, and J. L. Pedraz, "Potent, long lasting systemic antibody levels and mixed Th1/Th2 immune response after nasal immunization with malaria antigen loaded PLGA microparticles," Vaccine, vol. 22, no. 11-12, pp. 1423-1432, 2004.

[170] A. M. Carcaboso, R. M. Hernández, M. Igartua et al., "Immune response after oral administration of the encapsulated malaria synthetic peptide SPf66," International Journal of Pharmaceutics, vol. 260, no. 2, pp. 273-282, 2003.

[171] K. D. Newman, P. Elamanchili, G. S. Kwon, and J. Samuel, "Uptake of poly(D,L-lactic-co-glycolic acid) microspheres by antigen-presenting cells in vivo," Journal of Biomedical Materials Research, vol. 60, no. 3, pp. 480-486, 2002.

[172] I. R. Tizard, R. H. Carpenter, B. H. McAnalley, and M. C. Kemp, "The biological activities of mannans and related complex carbohydrates," Molecular Biotherapy, vol. 1, no. 6, pp. 290-296, 1989.

[173] D. G. Silva, P. D. Cooper, and N. Petrovsky, "Inulin-derived adjuvants efficiently promote both $\mathrm{Th} 1$ and $\mathrm{Th} 2$ immune responses," Immunology and Cell Biology, vol. 82, no. 6, pp. 611616, 2004.

[174] L. A. J. O’Neill, C. E. Bryant, and S. L. Doyle, “Therapeutic targeting of toll-like receptors for infectious and inflammatory diseases and cancer," Pharmacological Reviews, vol. 61, no. 2, pp. 177-197, 2009.

[175] K. B. Corden, K. S. Gorski, S. J. Gibson et al., "Synthetic TLR agonists reveal functional differences between human TLR7 and TLR8," Journal of Immunology, vol. 174, no. 3, pp. 1259-1268, 2005.

[176] M. L. Mbow, E. De Gregorio, N. M. Valiante, and R. Rappuoli, "New adjuvants for human vaccines," Current Opinion in Immunology, vol. 22, no. 3, pp. 411-416, 2010.

[177] B. A. Chang, J. L. Cross, H. M. Najar, and J. P. Dutz, "Topical resiquimod promotes priming of CTL to parenteral antigens," Vaccine, vol. 27, no. 42, pp. 5791-5799, 2009.

[178] C. Miranda-Verástegui, A. Llanos-Cuentas, I. Arévalo, B. J. Ward, and G. Matlashewski, "Randomized, double-blind clinical trial of topical imiquimod $5 \%$ with parenteral meglumine antimoniate in the treatment of cutaneous leishmaniasis in Peru," Clinical Infectious Diseases, vol. 40, no. 10, pp. 1395-1403, 2005.

[179] C. Othoro, D. Johnston, R. Lee, J. Soverow, J. C. Bystryn, and E. Nardin, "Enhanced immunogenicity of Plasmodium falciparum peptide vaccines using a topical adjuvant containing a potent synthetic toll-like receptor 7 agonist, imiquimod," Infection and Immunity, vol. 77, no. 2, pp. 739-748, 2009. 
[180] F. Hayashi, K. D. Smith, A. Ozinsky et al., "The innate immune response to bacterial flagellin is mediated by Toll-like receptor 5," Nature, vol. 410, no. 6832, pp. 1099-1103, 2001.

[181] D. Y. Bargieri, D. S. Rosa, C. J. M. Braga et al., "New malaria vaccine candidates based on the Plasmodium vivax Merozoite Surface Protein-1 and the TLR-5 agonist Salmonella Typhimurium FliC flagellin," Vaccine, vol. 26, no. 48, pp. 61326142, 2008.

[182] D. Y. Bargieri, J. A. Leite, S. C. P. Lopes et al., "Immunogenic properties of a recombinant fusion protein containing the Cterminal $19 \mathrm{kDa}$ of Plasmodium falciparum merozoite surface protein-1 and the innate immunity agonist FliC flagellin of Salmonella Typhimurium," Vaccine, vol. 28, no. 16, pp. 28182826, 2010.

[183] C. J. M. Braga, L. M. Massis, M. E. Sbrogio-Almeida et al., "CD8+ T cell adjuvant effects of Salmonella FliCd flagellin in live vaccine vectors or as purified protein," Vaccine, vol. 28, no. 5, pp. 1373-1382, 2010.

[184] M. Matsumoto and T. Seya, "TLR3: interferon induction by double-stranded RNA including poly(I:C)," Advanced Drug Delivery Reviews, vol. 60, no. 7, pp. 805-812, 2008.

[185] K. Tewari, B. J. Flynn, S. B. Boscardin et al., "Poly(I:C) is an effective adjuvant for antibody and multi-functional $\mathrm{CD} 4^{+} \mathrm{T}$ cell responses to Plasmodium falciparum circumsporozoite protein (CSP) and $\alpha$ DEC-CSP in non human primates," Vaccine, vol. 28 , no. 45, pp. 7256-7266, 2010.

[186] R. A. Robinson, V. T. DeVita, and H. B. Levy, "A phase I II trial of multiple dose polyriboinosinic polyribocytidylic acid in patients with leukemia or solid tumors," Journal of the National Cancer Institute, vol. 57, no. 3, pp. 599-602, 1976.

[187] S. Lousada-Dietrich, P. S. Jogdand, S. Jepsen et al., "A synthetic TLR4 agonist formulated in an emulsion enhances humoral and Type 1 cellular immune responses against GMZ2-A GLURPMSP3 fusion protein malaria vaccine candidate," Vaccine, vol. 29, no. 17, pp. 3284-3292, 2011.

[188] V. Meraldi, R. Audran, J. F. Romero et al., "OM-174, a new adjuvant with a potential for human use, induces a protective response when administered with the synthetic C-terminal fragment 242-310 from the circumsporozoite protein of Plasmodium berghei," Vaccine, vol. 21, no. 19-20, pp. 2485-2491, 2003.

[189] T. A. Olafsdottir, K. Lingnau, E. Nagy, and I. Jonsdottir, "IC31, a two-component novel adjuvant mixed with a conjugate vaccine enhances protective immunity against pneumococcal disease in neonatal mice," Scandinavian Journal of Immunology, vol. 69, no. 3, pp. 194-202, 2009.

[190] C. Schellack, K. Prinz, A. Egyed et al., "IC31, a novel adjuvant signaling via TLR9, induces potent cellular and humoral immune responses," Vaccine, vol. 24, no. 26, pp. 5461-5472, 2006.

[191] A. G. Blom and L. A. T. Hilgers, "Sucrose fatty acid sulphate esters as novel vaccine adjuvants: effect of the chemical composition," Vaccine, vol. 23, no. 6, pp. 743-754, 2004.

[192] L. A. T. Hilgers and A. G. Blom, "Sucrose fatty acid sulphate esters as novel vaccine adjuvant," Vaccine, vol. 24, no. 2, pp. S81S82, 2006.

[193] R. Bodewes, M. M. Geelhoed-Mieras, J. G. M. Heldens et al., "The novel adjuvant CoVaccineHTU increases the immunogenicity of cell-culture derived influenza A/H5N1 vaccine and induces the maturation of murine and human dendritic cells in vitro," Vaccine, vol. 27, no. 49, pp. 6833-6839, 2009.
[194] K. A. Kusi, E. J. Remarque, V. Riasat et al., "Safety and immunogenicity of multi-antigen AMA1-based vaccines formulated with CoVaccine HT and Montanide ISA 51 in rhesus macaques," Malaria Journal, vol. 10, article 182, 2011.

[195] H. M. Mahdi Abdel, E. J. Remarque, L. M. van Duivenvoorde et al., "Vaccination with Plasmodium knowlesi AMA1 formulated in the novel adjuvant co-vaccine HT protects against bloodstage challenge in rhesus macaques," PLoS One, vol. 6, no. 5, Article ID e20547, 2011.

[196] K. H. Lin, J. J. Liang, W. I. Huang et al., "In vivo protection provided by a synthetic new alpha-galactosyl ceramide analog against bacterial and viral infections in murine models," Antimicrobial Agents and Chemotherapy, vol. 54, no. 10, pp. 4129-4136, 2010.

[197] X. Li, M. Fujio, M. Imamura et al., "Design of a potent CD1dbinding NKT cell ligand as a vaccine adjuvant," Proceedings of the National Academy of Sciences of the United States of America, vol. 107, no. 29, pp. 13010-13015, 2010.

[198] G. Gonzalez-Aseguinolaza, L. Van Kaer, C. C. Bergmann et al., "Natural killer T cell ligand $\alpha$-galactosylceramide enhances protective immunity induced by malaria vaccines," Journal of Experimental Medicine, vol. 195, no. 5, pp. 617-624, 2002.

[199] N. N. Padte, X. Li, M. Tsuji, and S. Vasan, "Clinical development of a novel CD1d-binding NKT cell ligand as a vaccine adjuvant," Clinical Immunology, vol. 140, no. 2, pp. 142-151, 2011.

[200] O. Pérez, M. Lastre, O. Cabrera et al., "New vaccines require potent adjuvants like AFPL1 and AFCo1," Scandinavian Journal of Immunology, vol. 66, no. 2-3, pp. 271-277, 2007.

[201] G. Bracho, C. Zayas, L. Wang, and R. Coppel, "AFCo1, a meningococcal B-derived cochleate adjuvant, strongly enhances antibody and T-cell immunity against Plasmodium falciparum merozoite surface protein 4 and 5," Malaria Journal, vol. 8, no. 1, article 35, 2009.

[202] A. M. Harandi, G. Davies, and O. F. Olesen, "Vaccine adjuvants: scientific challenges and strategic initiatives," Expert Review of Vaccines, vol. 8, no. 3, pp. 293-298, 2009.

[203] G. Napolitani, A. Rinaldi, F. Bertoni, F. Sallusto, and A. Lanzavecchia, "Selected Toll-like receptor agonist combinations synergistically trigger a T helper type 1-polarizing program in dendritic cells," Nature Immunology, vol. 6, no. 8, pp. 769-776, 2005.

[204] Q. Zhu, C. Egelston, A. Vivekanandhan et al., "Toll-like receptor ligands synergize through distinct dendritic cell pathways to induce T cell responses: implications for vaccines," Proceedings of the National Academy of Sciences of the United States of America, vol. 105, no. 42, pp. 16260-16265, 2008.

[205] A. Merlo, C. Calcaterra, S. Ménard, and A. Balsari, "Cross-talk between Toll-like receptors 5 and 9 on activation of human immune responses," Journal of Leukocyte Biology, vol. 82, no. 3, pp. 509-518, 2007.

[206] J. Kazzaz, M. Singh, M. Ugozzoli, J. Chesko, E. Soenawan, and D. T. O'Hagan, "Encapsulation of the immune potentiators MPL and RC529 in PLG microparticles enhances their potency," Journal of Controlled Release, vol. 110, no. 3, pp. 566-573, 2006.

[207] C. Wischke, J. Zimmermann, B. Wessinger et al., "Poly(I:C) coated PLGA microparticles induce dendritic cell maturation," International Journal of Pharmaceutics, vol. 365, no. 1-2, pp. 6168, 2009.

[208] World Health Organization, "World Malaria Report 2011 (WHO Global Malaria Programme)," 2012, http://apps.who.int/ iris/bistream/10665/44792/2/9789241564403_eng_full.pdf. 


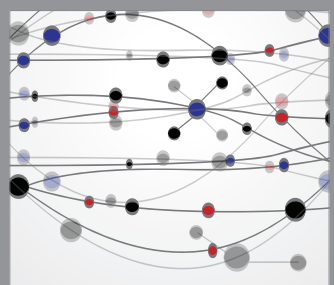

The Scientific World Journal
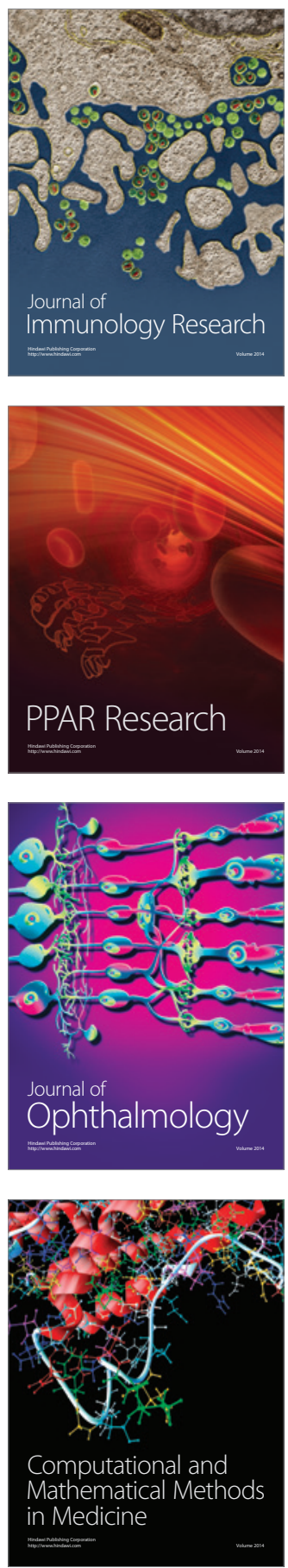

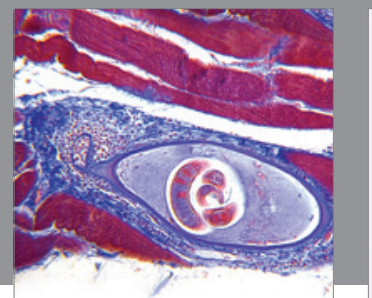

Gastroenterology

Research and Practice
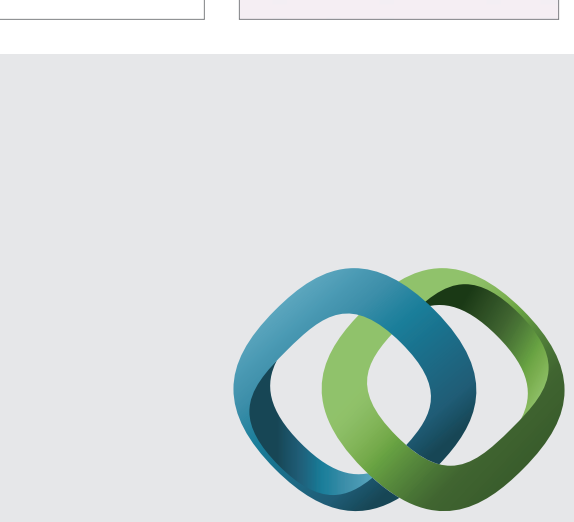

\section{Hindawi}

Submit your manuscripts at

http://www.hindawi.com
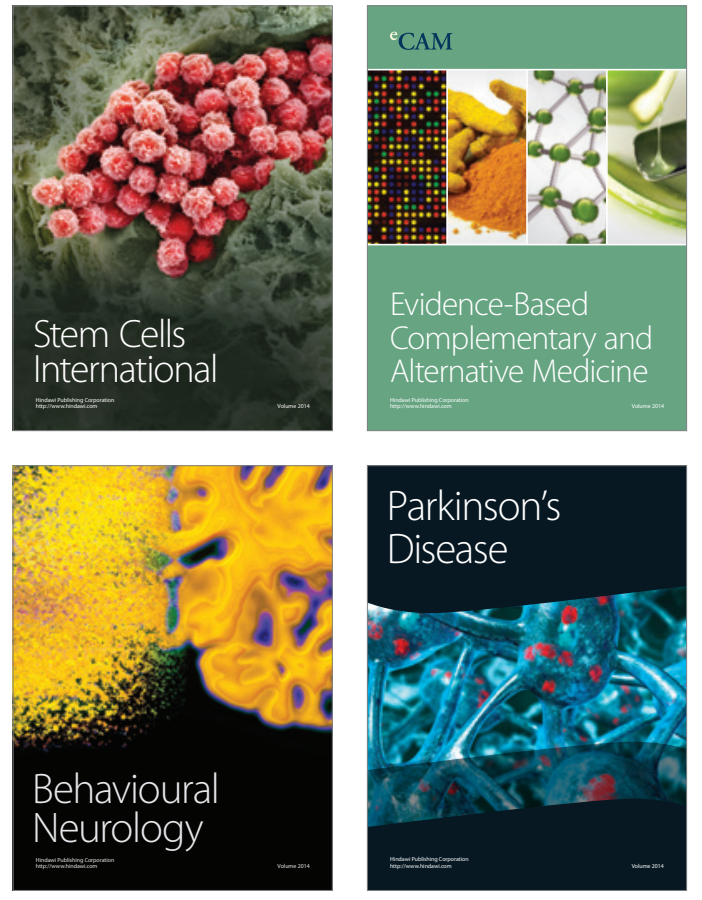
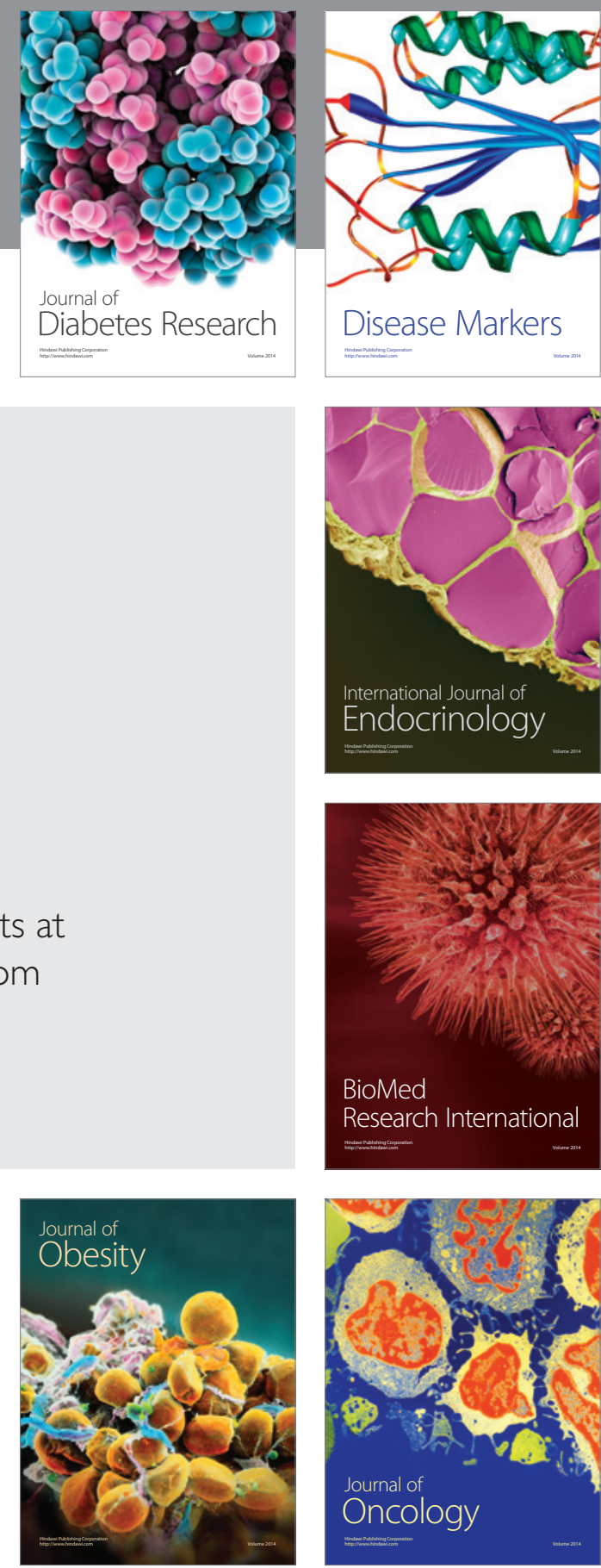

Disease Markers
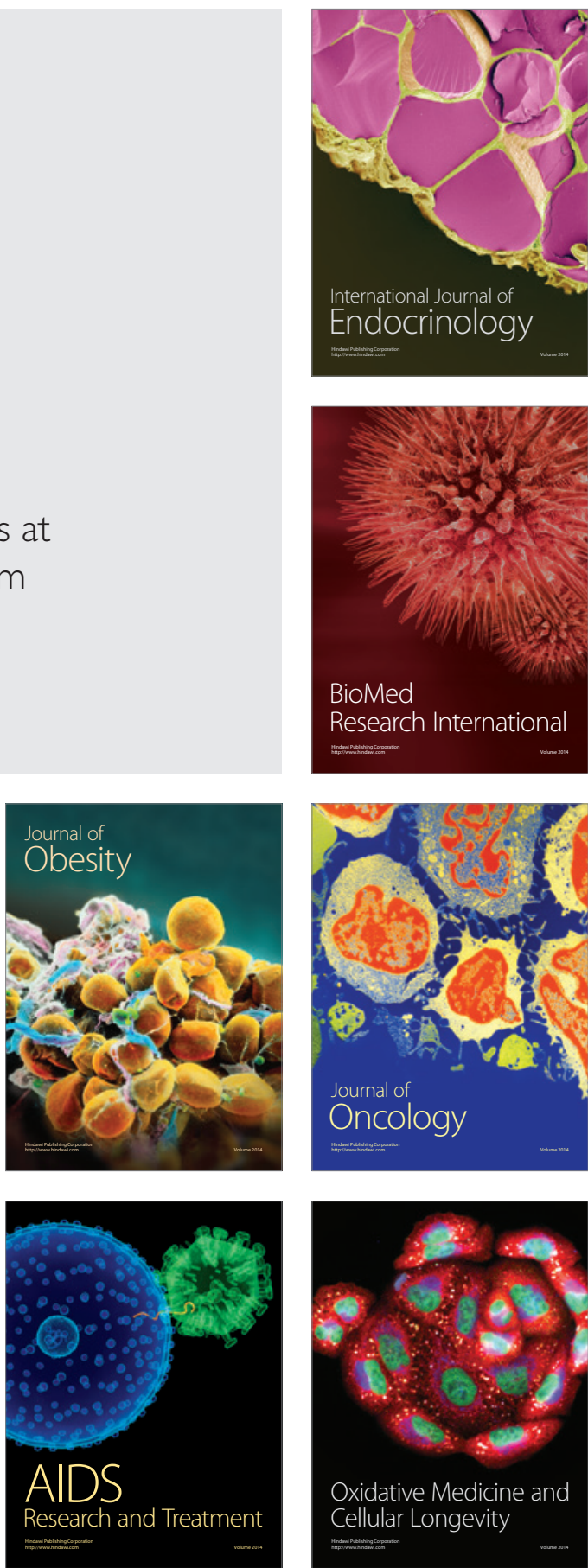